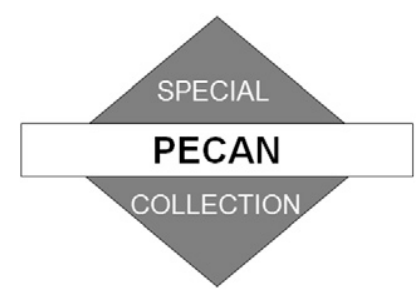

\title{
Seven-Doppler Radar and In Situ Analysis of the 25-26 June 2015 Kansas MCS during PECAN
}

\author{
RACHEL L. MILLER \\ Cooperative Institute for Mesoscale Meteorological Studies, and School of Meteorology, University of Oklahoma, and \\ NOAA/OAR/National Severe Storms Laboratory, Norman, Oklahoma \\ CONRAD L. ZIEGLER \\ MichaEL I. BigGERSTAFF \\ School of Meteorology, University of Oklahoma, Norman, Oklahoma
}

NOAA/OAR/National Severe Storms Laboratory, and School of Meteorology, University of Oklahoma, Norman, Oklahoma

(Manuscript received 14 May 2019, in final form 8 September 2019)

\begin{abstract}
This case study analyzes a nocturnal mesoscale convective system (MCS) that was observed on 25-26 June 2015 in northeastern Kansas during the Plains Elevated Convection At Night (PECAN) project. Over the course of the observational period, a broken line of elevated nocturnal convective cells initiated around 0230 UTC on the cool side of a stationary front and subsequently merged to form a quasi-linear MCS that later developed strong, surface-based outflow and a trailing stratiform region. This study combines radar observations with mobile and fixed mesonet and sounding data taken during PECAN to analyze the kinematics and thermodynamics of the MCS from 0300 to 0630 UTC. This study is unique in that 38 consecutive multiDoppler wind analyses are examined over the $3.5 \mathrm{~h}$ observation period, facilitating a long-duration analysis of the kinematic evolution of the nocturnal MCS. Radar analyses reveal that the initial convective cells and linear MCS are elevated and sustained by an elevated residual layer formed via weak ascent over the stationary front. During upscale growth, individual convective cells develop storm-scale cold pools due to pockets of descending rear-to-front flow that are measured by mobile mesonets. By 0500 UTC, kinematic analysis and mesonet observations show that the MCS has a surface-based cold pool and that convective line updrafts are ingesting parcels from below the stable layer. In this environment, the elevated system has become surface based since the cold pool lifting is sufficient for surface-based parcels to overcome the CIN associated with the frontal stable layer.
\end{abstract}

\section{Introduction}

The Plains Elevated Convection At Night (PECAN) field program (Geerts et al. 2017) was designed to study nocturnal weather features, including mesoscale convective systems (MCSs), bores, convection initiation (CI) events, and the nocturnal low-level jet (NLLJ). The comprehensive PECAN observing strategy included both mobile and fixed observations obtained by radars, sounding systems, PECAN integrated sounding array (PISA) profilers, research aircraft, and mesonets

Corresponding author: Rachel L. Miller, rachel.miller@noaa.gov
(Geerts 2013). Nocturnal MCSs contribute to the wellestablished nocturnal precipitation maximum over the central United States during the summer months (Maddox 1980; Carbone and Tuttle 2008; Wallace 1975). Achieving broad improvements in human and numerical forecasts of the formation, evolution, and intensity of nocturnal MCSs (e.g., as discussed by Ziegler 1999) continues to present considerable challenges, although there has been substantial recent progress in observing and modeling MCSs generally (e.g., Gale et al. 2002; Davis et al. 2003; Knievel et al. 2004; Clark et al. 2007) as well as a promising demonstration of potential human MCS forecast advances via 
experimental forecast results of the PECAN project (e.g., Geerts et al. 2017).

Observational studies using single- and multipleDoppler radar analysis conducted on daytime MCSs have led to the well-established conceptual model of a leading line, trailing stratiform (LL/TS) mode composed of a convective line (CL) and a trailing stratiform (TS) precipitation area that contains an ascending front-torear (FTR) flow fed by the CL and a descending rear-tofront (RTF) flow from the stratiform region toward the CL (Kessinger et al. 1987; Smull and Houze 1985, 1987; Houze et al. 1989, 1990; Biggerstaff and Houze 1991, 1993; Smull and Augustine 1993; Schmidt and Cotton 1989; Carbone et al. 1990; Jorgensen et al. 1997; Jorgensen and Smull 1993; Nachamkin et al. 1994, 2000; Klimowski 1994; Scott and Rutledge 1995; Rasmussen and Rutledge 1993; Schuur and Rutledge 2000; McAnelly et al. 1997; Grady and Verlinde 1997; Watson et al. 1988; Bernstein and Johnson 1994). Smull and Houze (1985) utilized single Doppler analysis to infer that a squall line's FTR flow was driven by the organized deep convection forming the CL, while Smull and Houze (1987) observed with a dual-Doppler analysis that the FTR flow which extended to the rear of the system facilitated horizontal flux of ice particles formed in the CL to the stratiform region. Single- and dualDoppler analyses of the classical 10-11 June 1985 MCS detailed aspects of the CL and mesoscale updrafts and downdrafts, the FTR outflow and RTF rear inflow jet (RIJ) branches, and the respective roles of depositional heating and sublimative and evaporative cooling to invigorate the mesoscale updraft and downdraft, respectively (Biggerstaff and Houze 1991, 1993).

Multiple studies have observed the impact of the RIJ on the development and maintenance of MCSs (Grim et al. 2009; Klimowski 1994; Rasmussen and Rutledge 1993; Nachamkin et al. 1994; Rutledge et al. 1988; Smull and Houze 1987). It has been observed that rear inflow develops behind high-reflectivity cores, sometimes before the stratiform region develops, and that during CL maturation it intensifies and expands rearward, thus implying that its development is convectively driven (Rutledge et al. 1988; Klimowski 1994). A positive correlation between the strength of the FTR and RTF flow has been observed and further supported by the strongest rear inflow being located behind the most intense convective regions and descending toward the surface as the CL intensifies (Klimowski 1994; Grim et al. 2009). Diabatically cooled rear inflow descending to the surface, combined with downdrafts from convective cells that merge to initiate the mesoscale cold pool (Engerer et al. 2008), can enhance convergence at the surface and strengthen the MCS (Smull and Houze 1987).
Two of the main objectives of PECAN are to determine whether nocturnal MCSs are elevated or surface based and to document how these systems interact with the stable nocturnal boundary layer (NBL) to sustain themselves long after sunset (Geerts 2013). Due to surface radiative cooling, it has previously been hypothesized that nocturnal convection is typically elevated and would propagate via gravity currents, undular bores, turbulent bores, and solitary waves (Carbone et al. 1990). Several more recent studies have suggested that nocturnal storms and MCSs may in fact be at least partially surface based (Rotunno et al. 1988; Parker 2008; Billings and Parker 2012; Marsham et al. 2011; Bryan and Weisman 2006; Roux 1988). Indeed, Corfidi et al. (2008) have argued against classifying systems as either purely surface based or elevated, and instead have hypothesized that a continuum of storm inflow modes exists between the surface-based and elevated storm types. Convective systems may also evolve to become more or less elevated due to changes in the systemrelative mesoscale inflow environment (Corfidi 2003).

The following case study of the 25-26 June 2015 MCS will analyze a combination of radar observations and in situ surface and sounding observations to examine the relationships between kinematics and reflectivity morphology of the MCS and the characteristics of the mesoscale NBL environment. Two unique aspects of the present study are the radar wind syntheses combining up to seven radars and continuously spanning roughly the first $3.5 \mathrm{~h}$ of the MCS's lifetime. The main objectives of the present study are as follows: 1) to document the evolution of the nocturnal MCS from its elevated CI stage to a mature LL/TS system with embedded bowing segments; 2) to determine whether the CL and the storm-scale and mesoscale cold pools are elevated, surface based, or some combination of these two modes using inflow air trajectory analysis; 3 ) to document the MCS morphological features associated with surface damage and severe winds; and 4) to provide another case study of nocturnal MCSs as recommended by Ziegler (1999) and Marsham et al. (2011).

\section{Data and analysis methods}

\section{a. Mobile and fixed ground-based Doppler radars}

Up to six mobile radars and a fixed radar provided simultaneous, full-volume ground-based Doppler observations of the 25-26 June 2015 MCS (Table 1). The mobile radars included SMART-R1 (SR1) and SR2 (Biggerstaff et al. 2005; Biggerstaff 2016a, b), the NOAA/NSSL X-POL (NOXP; Ziegler 2016), and the CSWR “Doppler-On-Wheels" DOW6, DOW7, and 
TABLE 1. Characteristics of the radar array from which multi-Doppler radar analyses were conducted during the core period 03000625 UTC for the 26 Jun 2015 MCS case. To augment ground-relative air trajectory calculations following Ziegler (2013b), "pseudoanalyses" assuming local steadiness following the storm motion were generated to fill in the period $0230-0255$ UTC and the $0305,0315,0325$, and 0335 UTC analysis times. Although not included in the multi-Doppler analyses, WSR-88D radar KEAX (Pleasant Hill, MO) data were analyzed between 0630 and 0715 UTC using the single-radar interpolation method described in the text (e.g., 0700 UTC in Fig. 4b).

\begin{tabular}{lccrr}
\hline \hline Radar & Wavelength $(\mathrm{cm})$ & Single/dual-polarimetric & $\begin{array}{c}\text { Observational period during } \\
\text { radar analysis sequence (UTC) }\end{array}$ & $\begin{array}{c}\text { Radar volume interval } \\
\text { (min) [time period] }\end{array}$ \\
\hline SR1 & 5 & Single-pol & $0300-0625$ & $10[0300-0340], 5$ after \\
SR2 & 5 & Dual-pol & $0300-0625$ & 10 [0300-0340], 5 after \\
NOXP & 3 & Dual-pol & $0300-0625$ & $10[0300-0340], 5$ after \\
DOW6 & 3 & Dual-pol & $0500-0620$ & 5 \\
DOW7 & 3 & Dual-pol & $0300-0625$ & $10[0300-0440], 5$ after \\
DOW8 & 3 & Single-pol & $0500-0520$ & 5 \\
KTWX & 10 & Dual-pol & $0300-0625$ & VCP-212 \\
\hline
\end{tabular}

DOW8 (Wurman et al. 1997). The observations from the National Weather Service (NWS) Topeka WSR88D (KTWX) and the mobile radars were combined in the multiple-Doppler analyses (Fig. 1, Table 1), with additional single-radar analysis of selected Kansas City/Pleasant Hill WSR-88D radar (KEAX) observations of the MCS's later stage. The radar array straddled an east-west-oriented stationary front (Fig. 1). The deployment strategy positioned the radars in six contiguous triangular subarrays (Fig. 1b, Table 1) that provided overlapping sampling volumes and covered baselines to affect optimal multiple-Doppler analysis
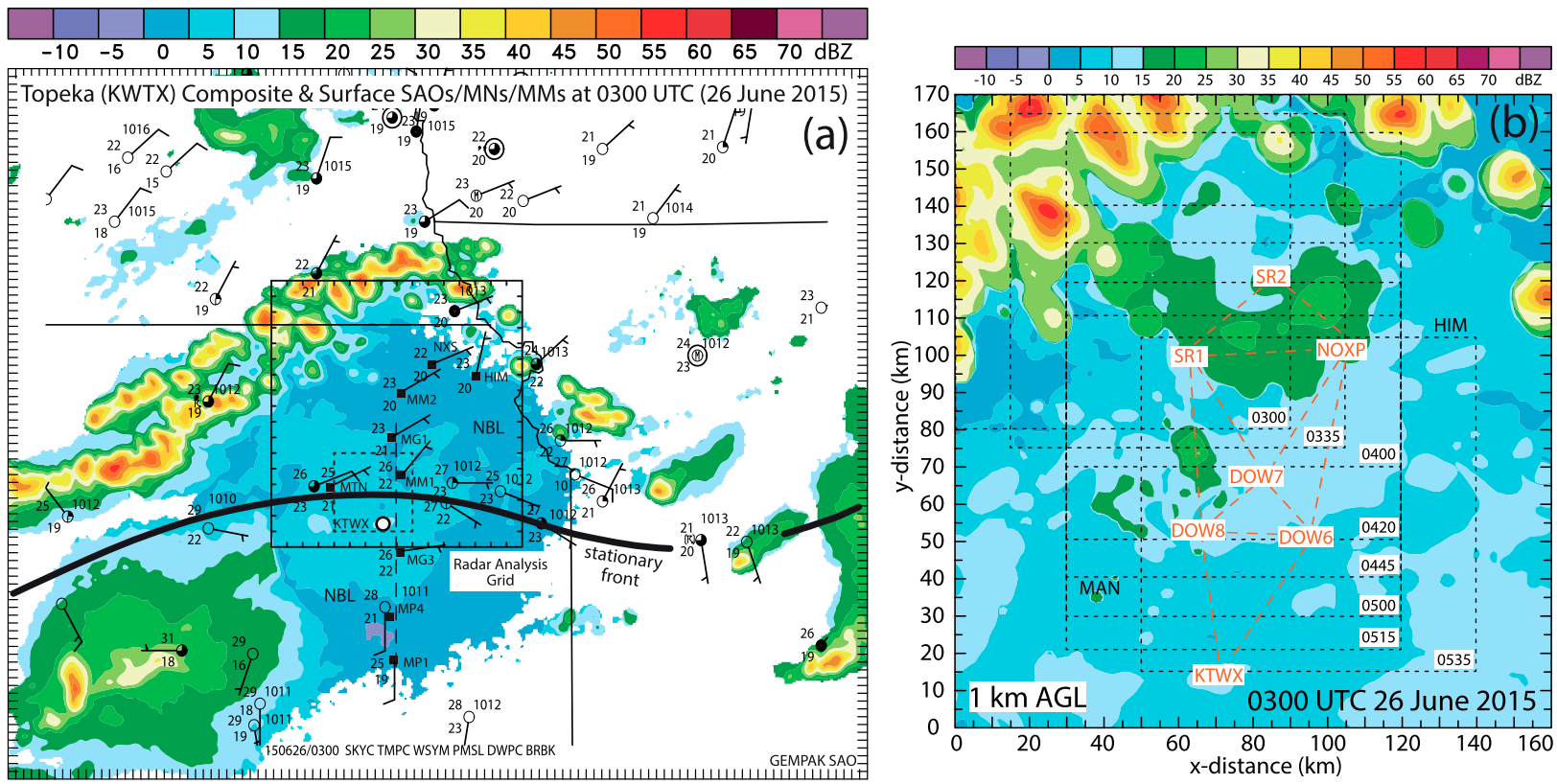

FIG. 1. Reflectivity relative to surface observations and the multi-Doppler radar analysis domain at 0300 UTC 26 Jun 2015. (a) KTWX composite reflectivity as obtained from column-maximum reflectivity spanning the entire domain, except for substitution of reflectivity $<20 \mathrm{dBZ}$ at $0.5 \mathrm{~km}$ AGL within $80 \mathrm{~km}$ range, and overlaid with surface SAO, mobile mesonet (MM), and Kansas mesonet (MN) observations. (b) Multi-Doppler radar reflectivity spanning the full analysis domain at $1 \mathrm{~km}$ AGL, overlaid with arrayed radar and selected surface observing station locations. In (a), the radar analysis domain is located by the black inset box, while the stationary front is a heavy black line that crosses over the southern portion of the radar analysis domain. The black dashed line in (a) locates the sounding analysis cross section shown in Fig. 2 and described in the text. Also in (a), the dashed black box shows where the nested, KTWX-DOW6 two-pass Barnes dual-Doppler radar analysis has been applied at 0520 UTC. In (b), the fixed radar analysis domain is overlaid with long-dashed orange lines denoting the six contiguous triangular subarrays formed from the indicated radars listed in Table 1. Also in (b), the black dotted boxes denote the relocatable, MCS-tracking subdomains from which backward gridpoint air trajectories are calculated. Time (UTC) at lower right of each box in (b) indicates the initial time of consecutive 5-min interval trajectory calculations within each fixed subdomain (i.e., the subdomain having been relocated at each indicated time). 
TABLE 2. Parameters of the fixed, multi-Doppler radar grid domain and the Barnes objective radar data interpolation as employed in the 26 Jun 2015 MCS case analyses described in the text.

\begin{tabular}{|c|c|c|}
\hline $\begin{array}{l}\text { Full-domain, 7-radar analysis } \\
\text { (one-pass Barnes analysis) }\end{array}$ & $\begin{array}{l}\text { Full domain size }(\mathrm{km} \times \mathrm{km} \times \mathrm{km}) \\
\text { Grid size }(n x, n y, n z) \\
\text { Grid spacing }(\mathrm{km})\end{array}$ & $\begin{array}{c}160 \times 170 \times 15 \\
231 \times 341 \times 31 \\
0.5(\text { all directions })\end{array}$ \\
\hline $\begin{array}{l}\text { Nested-domain, two-radar analysis } \\
\quad \text { (two-pass Barnes analysis) }\end{array}$ & $\begin{array}{l}\text { Nested domain size }(\mathrm{km} \times \mathrm{km} \times \mathrm{km}) \\
\text { Grid size }(n x, n y, n z) \\
\text { Grid spacing }(\mathrm{km})\end{array}$ & $\begin{array}{c}50 \times 50 \times 6 \\
101 \times 101 \times 13 \\
0.5 \text { (all directions) }\end{array}$ \\
\hline Full and nested domains (pass 1) & Barnes smoothing parameter $\kappa\left(\mathrm{km}^{2}\right)$ & $\begin{array}{c}3.8927(0300-0330) \\
1.347(0415-0625) \\
\text { Linear decrease (0330 to 0415) }\end{array}$ \\
\hline $\begin{array}{l}\text { Nested domain (pass 2) } \\
\text { Full and nested domains }\end{array}$ & $\begin{array}{l}\text { Gamma } \\
\text { Assumed MCS motion }\end{array}$ & $\begin{array}{c}0.3 \\
270^{\circ} \text { at } 8 \mathrm{~m} \mathrm{~s}^{-1}(0300-0345) \\
330^{\circ} \text { at } 16 \mathrm{~m} \mathrm{~s}^{-1}(0425-0625) \\
\text { Linear change }(0345 \text { to } 0425)\end{array}$ \\
\hline
\end{tabular}

(Ray et al. 1978; Ray et al. 1979; Ray et al. 1980; Ray and Sangren 1983; Ziegler et al. 1983; Ziegler et al. 1991; Kessinger et al. 1987; Ziegler 2013b).

\section{b. Fixed and mobile soundings, mobile mesonets, and Kansas mesonet}

The PECAN sounding array included three mobile sounding units, which facilitated sounding launches in various system-relative locations within the MCS environment. The NSSL sounding units (Ziegler et al. 2016) MG1 (operated by NSSL) and MG2 (operated by North Carolina State University) were collocated with DOW7 (Fig. 1a), and were able to provide a total of seven sequential soundings before, during, and after MCS passage between 0215 and 0701 UTC. The MG3 sounding unit (Ziegler et al. 2016) operated by Colorado State University was located just outside the southern boundary of the mobile radar array and radar analysis domain (Fig. 1a). Three mobile PECAN Integrated Sounding Array (PISA) platforms combined with MG1-MG2 to launch multiple soundings during the IOP within a fixed south-north-oriented linear array (e.g., MP1 (Klein et al. 2016) and MP4 (UCAR/NCAR - Earth Observing Laboratory 2016), Fig. 1a).

The two NSSL mobile mesonet (MM) vehicles, the NOXP scout vehicle, and all three mobile sounding units were equipped with NSSL's rooftop, rack-mounted MM instruments to measure temperature and relative humidity (Waugh 2012), as well as pressure and vector horizontal winds (Waugh and Ziegler 2017). Latitude and longitude were also recorded, enabling both measured and derived variables to be analyzed in space and time (Straka et al. 1996; Ziegler et al. 2004). Data from the Manhattan and Hiawatha Kansas mesonet sites, located within the analysis domain, contributed to the analysis of in situ measurements (UCAR/NCAR Earth Observing Laboratory 2015). Kansas mesonet variables such as temperature, relative humidity, and wind speed were archived as a 5-min running average.

\section{c. Radar analysis}

All radar data were initially dealiased using a customized Python-based script developed by the Biggerstaff research group at the University of Oklahoma School of Meteorology (D. Betten and A. Addison Alford 2017, personal communication). The customized script employs the region-based Python ARM Radar Toolkit (Py-ART) method (Helmus and Collis 2016) to identify the zero isodop and dealias the velocities to lower the standard deviation of radial velocity within that region. The customized Py-ART script also identifies and corrects dual-PRF and staggered PRT processor errors in mobile radar data via a similar method to lower the standard deviation of radial velocity (e.g., Altube et al. 2016; Tabary et al. 2005). A statistical ground clutter detection method developed by C. Alexander at the Earth Systems Research Laboratory (C. Alexander 2017, personal communication) in collaboration with the second author (CLZ) has been used to identify and remove potential clutter targets based on user-selected input criteria to create a clutter map in radar spherical coordinates. This clutter map is then applied as a data mask to remove velocity and reflectivity at suspected clutter gates where a radar gate reflectivity $(\mathrm{dBZ})$ value does not exceed the ground target reflectivity magnitude at that location. All radar observations have undergone further manual editing using Soloii to correct for mobile radar orientation and eradicate various other artifacts.

Optimal, scale-controlled spatial objective analysis has been implemented via a one-pass application of a multipass Barnes radar data interpolation algorithm (Majcen et al. 2008; Ziegler 2013b) to map all singleradar data to the full MCS analysis grid (Table 2; Miller 2018). The Barnes smoothing parameter $\kappa$ is linearly 
decreased in time to roughly optimize increasing resolution of the narrow MCS with decreasing average range as the system enters the radar array, and all single-radar radial velocity and reflectivity observations are interpolated to a fixed domain located in northeastern Kansas (Table 2). A two-pass Barnes analysis with the same Barnes smoothing (first pass) parameter $\kappa$ value as the full analysis has also been conducted (Table 2) to improve spatial resolution at a single analysis time within a nested grid (Fig. 1a) containing an inferred severe surface wind event (as discussed in section $4 b$ ). For the second Barnes pass in the nested domain, the smoothing parameter is multiplied by gamma to effectively recover additional velocity shear amplitude at short wavelengths. Individual radar observation locations are shifted via time-space conversion, with analysis times matched to low-level volume scans and the mobile radars time-synchronized to initiate volumes at the nominal 5-min analysis spacing (Table 1).

An overdetermined dual-Doppler radar synthesis algorithm with downward integration of the anelastic mass continuity equation is then applied to synthesize radial velocity and reflectivity from up to seven radars (Ray et al. 1980; Kessinger et al. 1987; Ziegler 2013b), followed by a variational, column-integral strong constraint adjustment to exactly impose anelastic mass continuity with kinematic lower and upper boundary conditions (Ray et al. 1980; Ziegler et al. 1983). Selected, prescribed dualand triple-Doppler pairs are objectively excluded from the wind synthesis at any grid point if any such pair is judged based on error analysis (Kessinger et al. 1987) to have a bad geometry (e.g., large-baseline dual-Doppler SR1-KTWX in Fig. 1b). The overdetermined dualDoppler algorithm subtracts the component of precipitation particle fall speed along the line from each radar to a grid point to obtain the radial component of air velocity (Ray et al. 1980; Kessinger et al. 1987). Ground-relative air trajectories are calculated backward in time from all analysis grid points within a relocatable, MCS-following subdomain (Fig. 1b) into the local inflow environment using a three-iteration, Runge-Kutta predictor-corrector scheme and a time step of $20 \mathrm{~s}$ (Ziegler 2013a).

\section{d. Composite sounding analysis incorporating mobile mesonet data}

The first analysis step vertically smooths each input sounding to mitigate horizontal propagation of spatially unrepresentative finescale stratifications in the subsequent two-dimensional vertical cross-sectional analysis. Each sounding's $1 \mathrm{~Hz}$ ( $\sim 5 \mathrm{~m}$ vertical data spacing) horizontal wind components are hole-filled via piecewise linear interpolation, then low-pass-filtered with a 15-pass application of a two-sided triangular function
TABLE 3. Parameters of the 2D sounding analysis grid domains and the Barnes objective sounding and mobile mesonet data interpolations as employed in the 26 Jun 2015 " $Y-Z$ ' and " $H-Z$ " case analyses described in the text.

\begin{tabular}{lc}
\hline \hline \multicolumn{1}{c}{ Parameters } & Values \\
\hline Domain $(\mathrm{km} \times \mathrm{km})$ & $160 \times 6(Y-Z) ; 100 \times 15(H-Z)$ \\
Grid $(n x, n y, n z)$ & $161 \times 61(Y-Z) ; 101 \times 151(H-Z)$ \\
$\Delta h, \Delta z(\mathrm{~km})$ & 1 (horizontal), $0.1($ vertical $)$ \\
Sounding $D_{h}(\mathrm{~km})$ & $30(Y-Z), 10(H-Z)$ \\
MM $D_{h}(\mathrm{~km})$ & 0.5 \\
$W_{z}($ soundings $)$ & 1 \\
$W_{z}(\mathrm{MM})$ & $\exp [-z / H], H=1.25 \mathrm{~km}$ \\
Outflow-normal motion & $145^{\circ}$ at $5 \mathrm{~m} \mathrm{~s}^{-1}$ \\
\hline
\end{tabular}

with a half-width of $150 \mathrm{~m}$. The next step is to horizontally map the smoothed soundings and the time-space converted MM observations to a cross-sectional grid (Table 3) via distance-dependent interpolation employing a smoothing one-pass Barnes weighting function of the following form:

$$
w=w_{z}(z) \exp \left[-\left(x-x_{s}\right)^{2} / \kappa\right]
$$

where $w$ is a datum weight, $w_{z}(z)$ is a height $(\mathrm{km})$ dependent data weight, $x$ is the grid $x$ coordinate $(\mathrm{km})$, $x_{s}$ is the sounding datum $x$ coordinate $(\mathrm{km})$, and the smoothing parameter $\kappa$ is defined as

$$
\kappa=\left(1.3333 \times D_{h}\right)^{2} .
$$

Here $D_{h}$ is the smoothing length scale $(\mathrm{km})$. The objectively analyzed sounding and MM Cartesian horizontal wind components $(u, v)$ are rotated into $\left(u^{\prime}, v^{\prime}\right)$, where $u^{\prime}$ is directed toward increasing horizontal coordinate in the plane of the cross section. The final step is to calculate vertical velocity using Boussinesq mass continuity with vertical velocity equal to zero as the upper and lower kinematic boundary conditions via an O'Brien variational adjustment (O'Brien 1970).

Two types of sounding analyses employing parameters listed in Table 3 are performed based on sounding location and timing. For the first analysis (" $Y-Z$ "), four simultaneous soundings are launched at 0300 UTC in a south-north-oriented cross section that samples the environment ahead of the MCS. The second analysis (" $H-Z$ ") combines six soundings from the collocated MG1-MG2 sounding vehicles, a seventh MG1 "pseudosounding" derived from the 4D radar and diabatic Lagrangian analysis (DLA) fields (e.g., see Miller 2018 for description of DLA application), and MG2's MM observations to construct an analysis of the mesoscale features of the MCS and its inflow environment relative to an assumed constant MCS motion over the fixed 
sounding location. An assumed MCS speed normal to the outflow boundary (Table 3 ) has been used to convert the time axis to a distance axis similar to the approach of Bryan and Parker (2010).

\section{Case overview and CI environment}

The 25-26 June PECAN deployment (IOP 16) was declared a bore mission, although both a nocturnal MCS and bores were anticipated by the PECAN forecasters (e.g., Geerts et al. 2017). Elevated weak, isolated convective cells had initiated around 0230 UTC and formed a CL to the northwest of the radar array as revealed by KTWX reflectivity at 0300 UTC (Fig. 1a). The CL had initiated on the cool side of a stationary front in an area with northeasterly surface winds and temperatures and dewpoints ranging from $22^{\circ}$ to $23^{\circ} \mathrm{C}$ and from $19^{\circ}$ to $21^{\circ} \mathrm{C}$, respectively (Fig. 1a). In contrast, southerly winds and slightly warmer temperatures prevailed to the south of the stationary front. A shallow ridge was located over the central plains at $500 \mathrm{mb}$ (not shown).

\section{a. Sounding analysis in the pre-MCS environment}

The south-north-oriented $Y-Z$ sounding analysis at 0300 UTC reveals the lifting of warm, moist air north of the surface frontal location via southerly shear and mesoscale updrafts up to $0.2 \mathrm{~m} \mathrm{~s}^{-1}$ (Fig. 2). Cross-frontal gradients and horizontal transport above the frontal layer of water vapor mixing ratio $\left(q_{v}\right.$, Fig. 2a), potential temperature $(\theta$, Fig. $2 \mathrm{~b})$, virtual potential temperature perturbation $\left(\theta_{v}^{\prime}\right.$, Fig. $\left.2 \mathrm{c}\right)$, wet-bulb potential temperature $\left(\theta_{w}\right.$, Fig. $\left.2 \mathrm{~d}\right)$, and equivalent potential temperature $\left(\theta_{e}\right.$, Fig. $\left.2 \mathrm{e}\right)$ are noted, leading to the formation of an elevated residual layer (ERL) between $750 \mathrm{~m}$ and $3 \mathrm{~km}$ to the north of the front. Westerly $\left(v^{\prime}=-[u\right.$ component $\left.]\right)$ shear (Fig. 2f) acts orthogonally to enhance the frontal lifting of moisture. Thus, the weak frontal lifting allows air from the warm-sector NBL to experience conserved lifting of $\theta$ and $q_{v}$ (i.e., "isentropic upglide"), which in turn primes the environment to help sustain the forming MCS.

The northernmost cross-sectional sounding location of MG1-MG2 (e.g., Fig. 2) reveals the strongly stratified and destabilizing environment in which the MCS ultimately evolved (Fig. 3). The surface-based nocturnal layer around $900 \mathrm{mb}$ is capped by $\sim 200 \mathrm{~J} \mathrm{~kg}^{-1}$ of surface-based mixed layer convective inhibition (MLCIN), restricting air between the surface and $900 \mathrm{mb}$ from ascending into the convective cells in the absence of a hypothesized strong mesoscale lifting mechanism (Parker 2008). Abundant surface-based mixed layer convective available potential energy (MLCAPE) and elevated steep lapse rates provide ingredients to help initiate elevated convection and sustain the potential transition to a surface-based MCS.

\section{b. Overview of MCS evolution and multi-Doppler radar analysis}

Multiple-Doppler synthesis of the 26 June MCS was conducted from 0300 to 0630 UTC (Table 1). As discussed in detail in section 4, the initially isolated cells merged into a west-southwest-east-northeast-oriented CL between 0300 and 0400 UTC that subsequently experienced rapid upscale growth. A bowing segment formed at the southwestern end of the quasi-linear convective system (QLCS) around 0500 UTC (Fig. 4a). Although a major portion of the QLCS/MCS remained to the north of the stationary front, the first bowing MCS segment straddled the front. Temperatures behind the $\mathrm{CL}$ at 0500 UTC were cooler than at 0300 UTC (Fig. 1) in accord with mesoscale cold pool passage. Both the first and second bowing MCS segments (only the first of which is examined in detail in the present study) went on to produce severe wind reports in northeastern Kansas and northwestern MO (Fig. 4b, Table 4). The first severe wind report at 0521 UTC was located near Topeka, Kansas, while later reports clustered around and east of Kansas City (Fig. 4b). Multi-Doppler data collection was discontinued at 0630 UTC as the CL moved out of range of the radar array.

Time-height analyses reveal the evolving horizontally integrated updraft volume and updraft mass flux and the maximum values of reflectivity and updraft at all levels (Fig. 5). Sustained MCS intensification is revealed by increasing trends of maximum reflectivity and updrafts (Fig. 5a), updraft volume (Fig. 5b), and updraft mass flux (Fig. 5c). Due to a generally increasing trend of the number and intensity of updraft cores and their volumes, the magnitudes of the horizontally integrated updraft volume (UDVOL) and updraft mass flux (UDMFLX) rapidly increase before 0400 UTC as the MCS organizes from the initial CL (Figs. 5b,c). Five local maxima of UDVOL and UDMFLX are evident around 0415, 0425, 0440, 0510, and 0530 UTC.

\section{Evolution of 3D radar-analyzed MCS structure}

\section{a. 0300-0400 UTC}

The radar analysis at 0300 UTC captures a portion of the line of initially isolated convective cells in the northwestern corner of the radar analysis domain (Fig. 6). Horizontal ambient, clear-air southeasterly winds at $0.5 \mathrm{~km}$ (Fig. 6a) veer to southerly at $5 \mathrm{~km}$ (Fig. 6b), which corresponds to both the stable NBL at $0.5 \mathrm{~km}$ and the ERL north of the front (Fig. 2). The horizontal winds in the convective cores at $0.5 \mathrm{~km}$ indicate locally veered, 

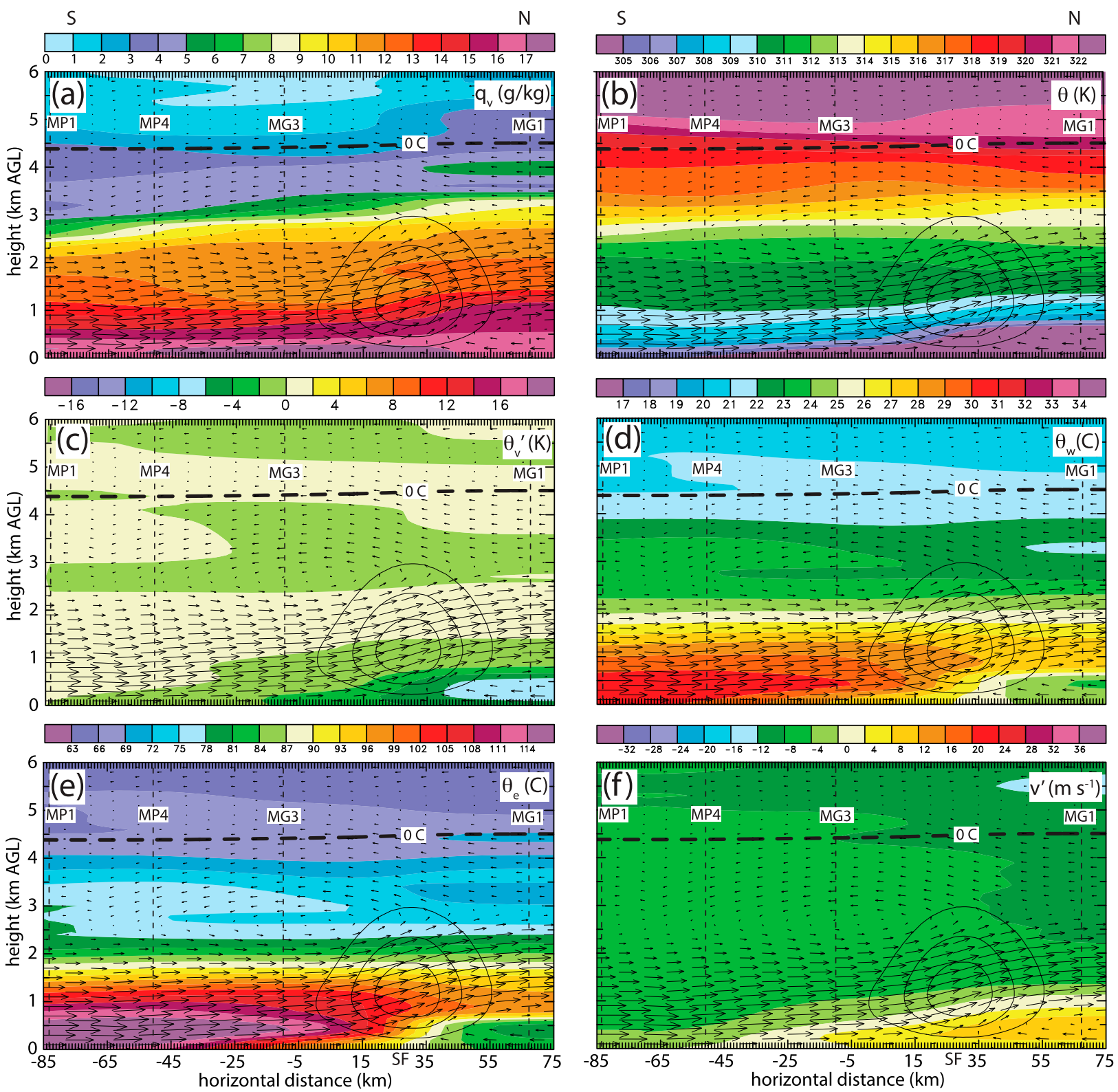

FIG. 2. South-north cross section through the stationary front at 0300 UTC using four soundings from MG1, MG3, MP4, and MP1 indicated by black dashed lines and labeled with the respective sounding unit. All panels have solid black contours every $0.05 \mathrm{~m} \mathrm{~s}^{-1}$ to show weak ascent due to the front, labeled "SF." The six panels show the following fields: (a) $q_{v}$, (b) $\theta$, (c) $\theta_{v}^{\prime}$, (d) $\theta_{w}$, (e) $\theta_{e}$, and (f) crosssectional normal horizontal wind component $v^{\prime}$ (e.g., easterly winds having positive values into the plane). Vectors are ground-relative airflow in the cross-sectional plane, and are scaled relative to $10 \mathrm{~km}=10 \mathrm{~m} \mathrm{~s}^{-1}$.

stronger southerly to southwesterly winds that are consistent with downward westerly momentum transport within approximately surface-based convective downdrafts embedded in the ambient westerly shear (Figs. 2, 3 , and $6 \mathrm{c}, \mathrm{d})$. Inspection of all updraft inflow trajectories (to be presented in section $6 \mathrm{~b}$ ) show that the isolated, deep reflectivity cores tend to associate with elevated updrafts having visually inferred inflows concentrated approximately within the $2-3 \mathrm{~km}$ ERL, as illustrated by a plotted trajectory originating at $1.5 \mathrm{~km}$ (Figs. 6c,d).

The initially isolated convective cells at 0300 UTC have merged into a linear MCS via an upscale growth process by 0400 UTC (Fig. 7). Southeasterly clear air inflow at $0.5 \mathrm{~km}$ (Fig. $7 \mathrm{a}$ ) veers to southerly at $5 \mathrm{~km}$ (Fig. 7b) ahead of the CL as previously at 0300 UTC (Fig. 6). In contrast, northeasterly outflow is now evident within the high-reflectivity core of the CL northwest of 

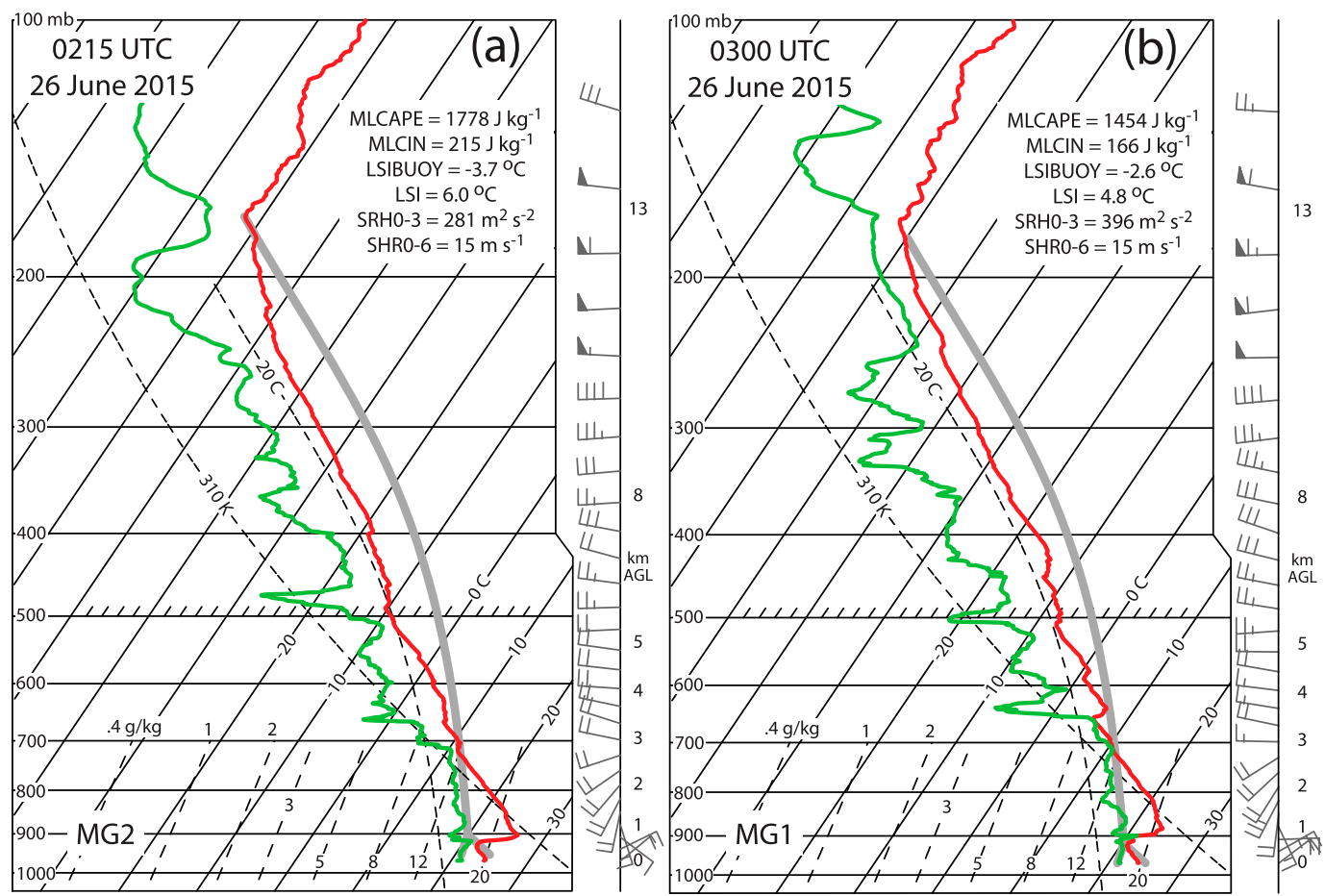

FIG. 3. Environmental soundings from MG1/MG2, which were collocated with DOW7: (a) 0215 UTC (MG2) and (b) 0300 UTC (MG1). These soundings are located about $40 \mathrm{~km}$ north of the stationary front (Fig. 1a) and $80 \mathrm{~km}$ southeast of the forming convective line (Fig. 1b). The red, green, and gray lines indicate temperature, dewpoint, and a surface-based, 50-mb average lifted parcel, respectively. Calculated lifted-parcel sounding quantities (including mixed-layer CAPE and CIN computed from lifted parcel and environmental virtual temperature profiles) are shown in the upper right corner of each panel. Wind vectors in each panel are denoted with half-barb = $2.5 \mathrm{~m} \mathrm{~s}^{-1}$, full barb $=5 \mathrm{~m} \mathrm{~s}^{-1}$, and pennant $=25 \mathrm{~m} \mathrm{~s}^{-1}$.

SR1 and SR2 at $0.5 \mathrm{~km}$ (Fig. 7a), while aloft a westerly rear inflow has begun converging with a southerly forward inflow in the high-reflectivity $\mathrm{CL}$ core at $5 \mathrm{~km}$ (Fig. 7b). This flow pattern leads to enhanced convergence at low levels near the leading edge of the line to provide further lift for convection. Updrafts at $5 \mathrm{~km}$ are associated with convective cores within the line and also with the isolated cell in the inflow located above SR1 (Fig. 6). A classical northwestward-sloping interface between weakly $\left(-1 \mathrm{~m} \mathrm{~s}^{-1}\right)$ descending low-level rearto-front (RTF) flow and ascending middle- to upperlevel front-to-rear (FTR) flow defines the most intense portion of the CL (Figs. 7c,d). The strongest rear inflow is located directly upstream from the highest reflectivity core with reflectivity values above $30 \mathrm{~dB} Z$ in the $3-5 \mathrm{~km}$ layer (Fig. 7c), while isolated convective updrafts continue to be exposed to the ambient vertical westerly shear (Fig. 7d). Expanding areas of both TS precipitation (Fig. 7) and forward overhang anvil (Fig. 7c) have begun forming in association with mesoscale upper-level divergence forced by multiple proximate convective cores. The majority of visually inferred updraft inflows are estimated to be originating from the $1-3 \mathrm{~km}$ ERL, as illustrated by a plotted trajectory originating at $1 \mathrm{~km}$ (e.g., Figs. $7 \mathrm{c}, \mathrm{d})$.

\section{b. 0500-0520 UTC}

A deeper RTF inflow, an expanded TS region, and a stronger FTR branch assisted by upper-level mesoscale divergent outflow from the CL characterizes the MCS at 0500 UTC (Fig. 8). A north-south-oriented bowing CL segment is evident at $0.5 \mathrm{~km}$ at the southwestern end of the QLCS at $(50,60)$ (Figs. 8a,b). An outflow surge located about $10 \mathrm{~km}$ west of DOW8 accompanies the initial bowing segment. This outflow surge appears to be channeled by an anticyclonic circulation to its west that is evident as early as 0440 UTC (not shown) through 0500 UTC (Fig. 8) until just after 0520 UTC (Fig. 9). As a result of the stronger outflow from the maturing MCS, the pre-CL convergence is stronger than at earlier analysis times (Figs. 8a,c-e). Newly initiated convection on the backside of the MCS (Figs. 8a,b,e) appears to be fed by southwesterly flow that overrides and is lifted over the cold pool to its LFC similar to the "bow-and-arrow" mechanism described by Keene and Schumacher (2013). The RTF flow has strengthened, deepened, and descended to 

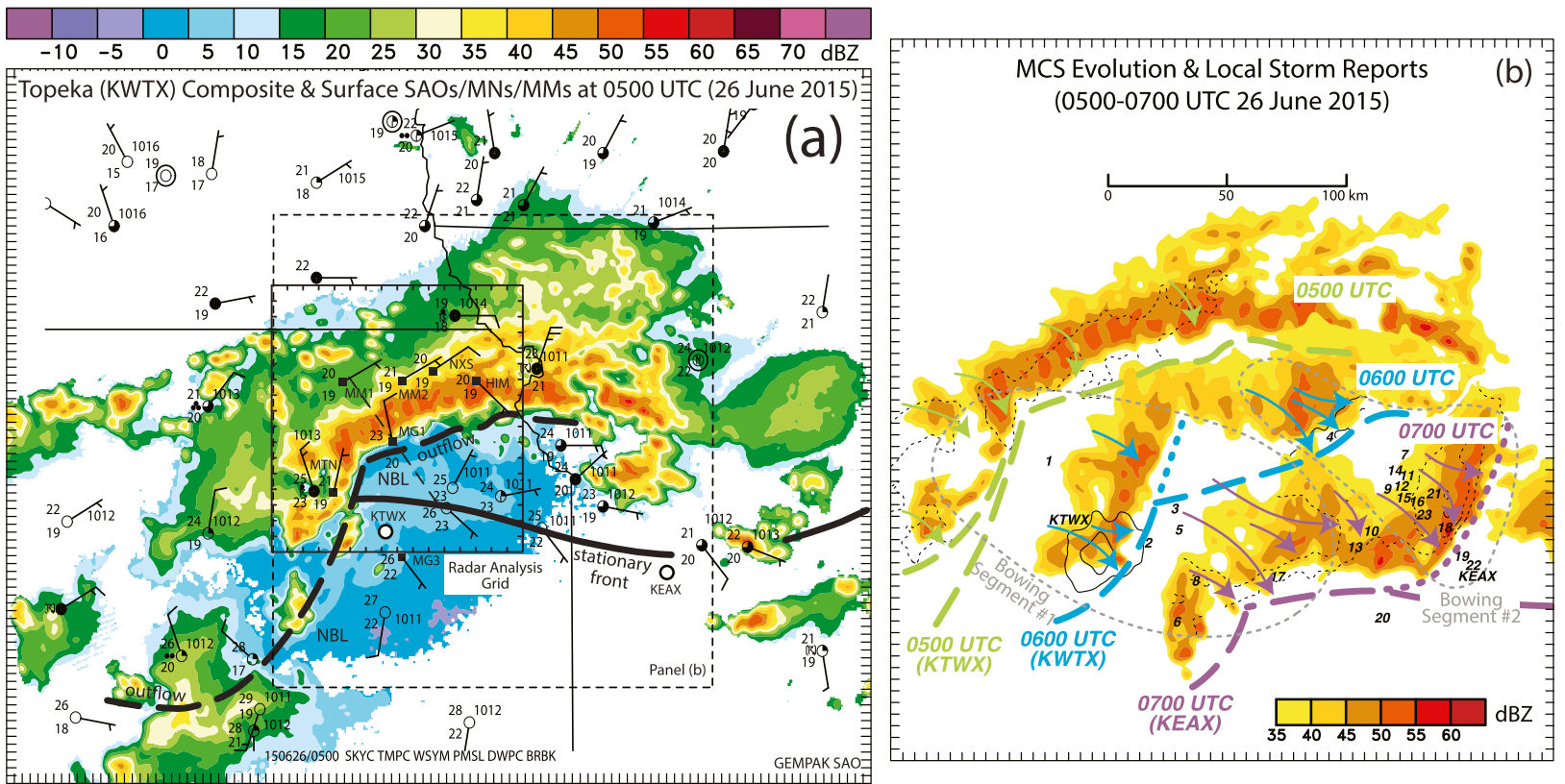

FIG. 4. Reflectivity at 0500 UTC and MCS evolution in the period 0500-0700 UTC 26 Jun 2015 relative to surface observations and the radar analysis domain. (a) KTWX reflectivity at 0500 UTC 26 Jun 2015 (composited in the same manner as Fig. 1a) relative to surface observations and the radar analysis domain overlaid with surface SAO, mobile mesonet, and Kansas mesonet observations. (b) Composite KTWX reflectivity (0500-0600 UTC) and KEAX reflectivity (0700 UTC) above $35 \mathrm{dBZ}$ overlaid with numbered wind reports detailed in Table 2. In (a), the stationary front is a solid black line that crosses over the southern portion of the radar analysis domain with a long black dashed line denoting the location of the outflow boundary. Also in (a): the short black dashed line locates the sounding analysis cross section shown in Fig. 16 and described in the text; the solid box indicates the full radar analysis grid; the large dashed box locates the region used for (b); and the small dashed box inside the full radar analysis domain locates the nested-grid, two-pass Barnes analysis at 0520 UTC. In (b): the green, blue, and purple dashed lines indicate the locations of the velocity-inferred outflow boundaries at 0500,0600 , and 0700 UTC, respectively; while the colored arrows correspond to the inferred outflow streamlines at each time, and the closed, gray dashed outlines locate the two bowing segments referred to in the text. Also in (b), the first bowing segment developing at 0500 UTC at the southwestern terminus of the QLCS, and the second bowing segment developing later at 0600 UTC farther northeast in the QLCS; while the solid (dashed) black contours indicate areas of positive (negative) radial velocity measured by KTWX and KEAX every $10 \mathrm{~m} \mathrm{~s}^{-1}$ starting at $\pm 10 \mathrm{~m} \mathrm{~s}^{-1}$. In both panels, locations of WSR-88Ds are indicated by "KTWX" and "KEAX."

the surface relative to 0400 UTC (Fig. 7) and now extends back into the formative stratiform precipitation region (Figs. 8c-e). Sample inflow trajectories into CL updrafts that originate from within the lowest $500 \mathrm{~m}$ (Figs. $8 \mathrm{c}-\mathrm{e}$ ) are more complex than earlier trajectories, initially experiencing backing horizontal winds following the Lagrangian motion (not shown) before subsequently being overtaken by the advancing outflow boundary and lifted by updrafts within the outflow convergence zone.

The first NOAA/NWS Storm Prediction Center (SPC) local storm report (LSR) in the 26 June MCS (Table 4) associates with inferred potentially severe surface winds at or around 0521 UTC (denoted "W" in Figs. 9a-d). The $0.5 \mathrm{~km}$ radar analysis at 0520 UTC (Fig. 9a) locates the LSR at the southern edge of the outflow surge that had advanced rapidly east-southeastward prior to 0520 UTC. The most intense convection associated with the initial bowing segment is evident along the entire leading edge of the surging, bowing outflow segment. The anticyclonic circulation to the west is dominant over the weak cyclonic circulation to the east at 0500 (Fig. 8a) and 0520 UTC (Fig. 9a). Horizontal airflow within the RTF branch of the bowing segment shifts from westerly to northnorthwesterly as it encounters this anticyclonic circulation. Updraft inflow trajectories originating both from ahead of the outflow surge at $1.5 \mathrm{~km}$ (Figs. 9c,d) and from below $500 \mathrm{~m}$ entering the MCS's main CL (Fig. 9e) broadly illustrate a range of updraft inflow origins at 0520 UTC from the lowest several kilometers above ground. An $8 \mathrm{~m} \mathrm{~s}^{-1}$ updraft core flanked by $-4 \mathrm{~m} \mathrm{~s}^{-1}$ downdrafts at $5 \mathrm{~km}$ is located immediately north of the LSR (Figs. 9b-d).

The 0521 UTC LSR (Table 4) and inferred severe surface wind event is just ahead of a surging reflectivity core tilting downward toward the south in an intense outflow rotor circulation fed by downdrafts exceeding $-4 \mathrm{~m} \mathrm{~s}^{-1}$ (Figs. 9c,d). This downdraft-fed rotor circulation closely resembles a traveling downburst described by Fujita (1981), with the most severe surface-based winds ahead of inferred precipitation-cooled downdraft air (e.g., Fujita and Wakimoto 1981). Maximum radar-derived surface 
TABLE 4. Local storm reports associated with the 26 Jun 2015 MCS (source: https://www.spc.noaa.gov/climo/reports/150625_rpts.html). These storm reports spanning the period 0521-0730 UTC 26 Jun correspond to the radar-analyzed MCS as discussed in the text and graphically overviewed in Fig. 4b. UNK: unknown. Numerical values in the "location" column are distance (mi) from noted landmark. Measured peak wind speed $(\mathrm{kt})$ is noted in the "comments" column $\left(1 \mathrm{kt}=0.5144 \mathrm{~m} \mathrm{~s}^{-1}\right)$.

\begin{tabular}{|c|c|c|c|c|}
\hline Report No. & Report time (UTC) & Peak wind (mph) & Location & Abbreviated comments \\
\hline 1 & 0521 & UNK & $1 \mathrm{~N}$ Wamego, KS & Old tree fallen across road \\
\hline 2 & 0607 & UNK & Auburn, KS & Tree down across power line \\
\hline 3 & 0618 & UNK & $1 \mathrm{SW}$ Topeka, KS & Trees down \\
\hline 4 & 0623 & UNK & Leavenworth, KS & Tree into power lines \\
\hline 5 & 0627 & 60 & Shawnee, KS & \\
\hline 6 & 0628 & 70 & Lyndon, KS & \\
\hline 7 & 0630 & UNK & Gladstone, $\mathrm{MO}$ & $12-15$ in. diameter limbs down \\
\hline 8 & 0632 & UNK & Overbrook, KS & Large trees down \\
\hline 9 & 0634 & UNK & Kansas City, KS & Oak trees snapped \\
\hline 10 & 0640 & UNK & Lenexa, KS & $6 \mathrm{ft}$ diameter tree uprooted \\
\hline 11 & 0640 & UNK & $3 \mathrm{~S}$ Gladstone, $\mathrm{MO}$ & Large pin oak tree down \\
\hline 12 & 0642 & 59 & 2 NNW Kansas City, MO & MKC measured $51 \mathrm{kt}$ \\
\hline 13 & 0649 & 70 & Olathe, KS & \\
\hline 14 & 0649 & 80 & Riverside, MO & \\
\hline 15 & 0651 & 75 & 1 SE Kansas City, MO & \\
\hline 16 & 0651 & UNK & 1 SE Kansas City, MO & 20 in. diameter limb snapped \\
\hline 17 & 0655 & UNK & Baldwin City, KS & Tree damage \\
\hline 18 & 0656 & 61 & 3 N Lee's Summit, MO & LXT measured $53 \mathrm{kt}$ \\
\hline 19 & 0704 & UNK & 3 E Greenwood, MO & Large branches down \\
\hline 20 & 0710 & UNK & Louisburg, KS & 18 in. diameter tree down \\
\hline 21 & 0710 & UNK & Independence, $\mathrm{MO}$ & 6 in. diameter broken limb \\
\hline 22 & 0712 & 65 & Pleasant Hill, MO & Damaged roof, fence, 8 in. tree \\
\hline 23 & 0730 & UNK & Raytown, MO & Power line down \\
\hline
\end{tabular}

wind speeds approaching $29 \mathrm{~m} \mathrm{~s}^{-1}$ locally exceed severe limits $\left(>26 \mathrm{~m} \mathrm{~s}^{-1}\right)$ within a narrow zone at the leading edge of the surging reflectivity core, although the maximum radar-derived surface winds at 0520 UTC are not collocated with the LSR (e.g., possibly due in part to rapid storm motion combined with LSR timing uncertainty). The MCS-scale RTF and FTR branches at 0520 UTC (Fig. 9e) are maintained relative to 0500 UTC (Fig. 8e).

\section{c. $0600-0625$ UTC}

Persistent intensification of the RTF inflow, TS regional coverage, and assistance by upper-level mesoscale divergent CL outflow help strengthen the FTR branch at 0600 UTC (Fig. 10) and 0625 UTC (Fig. 11). In particular, the RTF inflow within the lowest $5-6 \mathrm{~km}$ increasingly undercuts and provides low-level convergence to support the vigorous leading CL (Figs. 10c and 11d). Although the expanding TS region (containing large areas of reflectivity values of $35 \mathrm{dBZ}$ and localized cores above $45 \mathrm{dBZ}$ ) is evident in the rear of the entire CL, and a transition region has emerged between the CL and TS core regions (e.g., Figs. 10b-e and 11b,e), the TS core is particularly pronounced behind the bowing segment. Associated with veering winds in the $0.5-5 \mathrm{~km}$ layer in the developing stratiform region to the west of the bowing segment from 0520 (Fig. 9) to 0600-0625 UTC (Figs. 10 and 11), the embedded cells behind the CL have weakened due hypothetically to increasing westerly advection of drier midlevel air that opposes the previous elevated trailing convection (e.g., Keene and Schumacher 2013). The rear inflow accelerates within $80 \mathrm{~km}$ of the $\mathrm{CL}$ in regions with reflectivity values exceeding $35 \mathrm{~dB} Z$. The enduring presence of accelerated RTF flow at the rear of the CL, whether in the presence or absence of TS precipitation, implies that the CL is important in assisting the maintenance of the rear inflow.

The midlevel CL updraft cores at 0600 (Fig. 10) and 0625 UTC (Fig. 11) associate with large inferred precipitation contents given reflectivities exceeding $60 \mathrm{dBZ}$ (Ziegler 2013a). The updrafts associated with the bowing segment to the east of KTWX and DOW6 are stronger and cover more area than the updrafts in the QLCS generally. Sample inflow trajectories at 0600 (Figs. 10c-e) and 0625 UTC (Fig. 11e) collectively illustrate that the CL updrafts are continuing to ingest air from the lowest $3 \mathrm{~km}$ above ground. Several small rotor circulations are located between the RTF and FTR flow in areas of stronger shear, facilitating exchange of air via updrafts from the RTF flow to the more elevated FTR flow as well as via downdrafts from the FTR to RTF branches. An alternating pattern of 5-10 $\mathrm{m} \mathrm{s}^{-1}$ updrafts and downdrafts aligned with the RTF flow is indicative of a train of longitudinal horizontal roll circulations in the lowest $5 \mathrm{~km}$ that support elevated deep convective cells with tops above $12 \mathrm{~km}$ (Figs. 11c,d). 

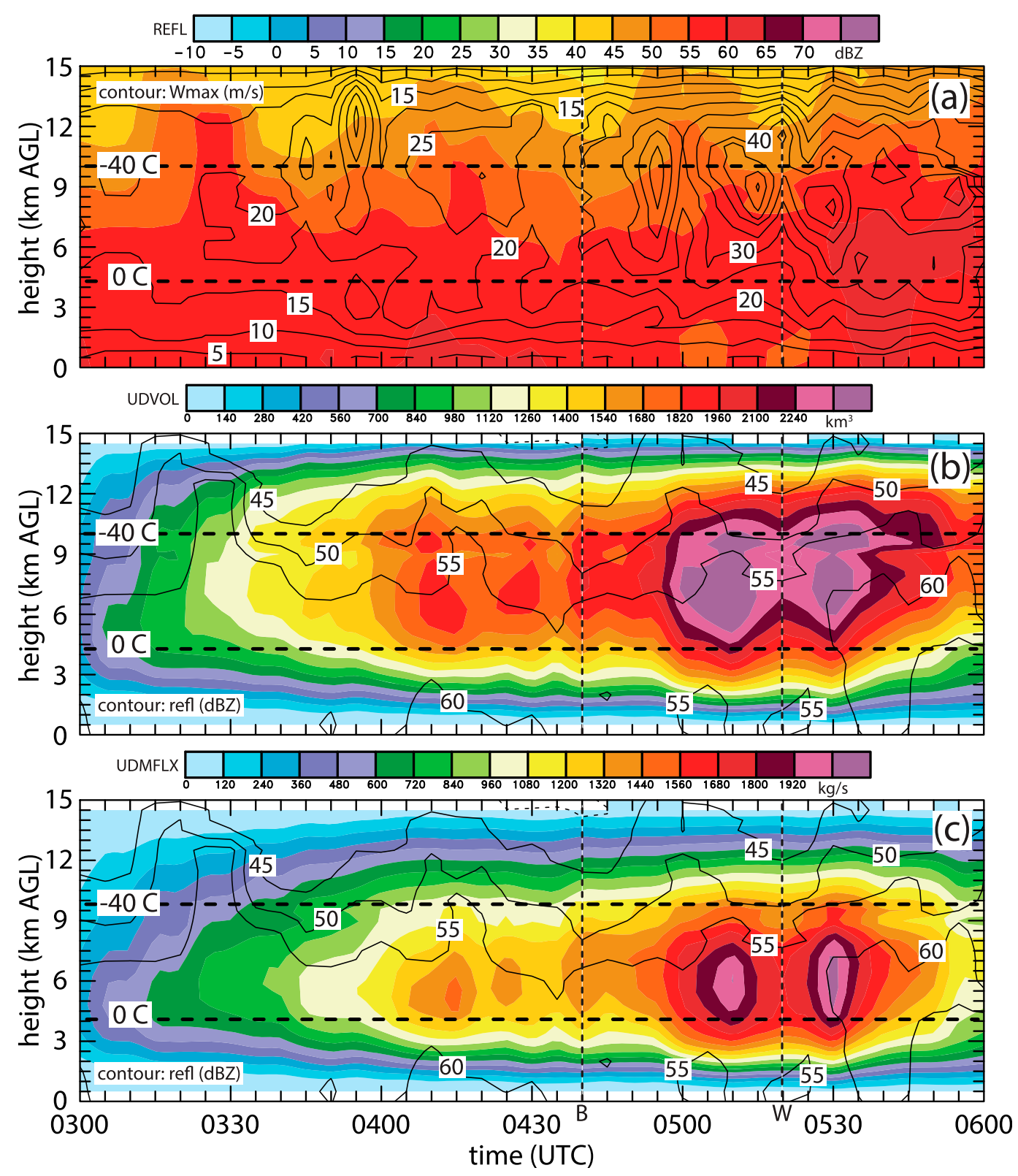

FIG. 5. Horizontally integrated values over the full radar analysis domain (black inset box in Fig. 1a; domain shown in Fig. 1b; smaller black inset box in Fig. 4a) at each analysis level and each 5-min interval analysis time during a 3-h time period from 0300 to $0600 \mathrm{UTC}$, with the $0^{\circ}$ and $-40^{\circ} \mathrm{C}$ isotherms overlaid. (a) Color-filled maximum reflectivity, with the maximum updraft $(w)$ value contoured; (b) color filled integrated updraft volume, derived by summing every grid cell volume with $w$ exceeding $3 \mathrm{~m} \mathrm{~s}^{-1}$, with the maximum reflectivity contoured; (c) color-filled integrated updraft mass flux, with maximum reflectivity contoured. Vertical line " $\mathrm{B}$ " indicates the initiation of the surging outflow feature, while vertical line "W" indicates the approximate time of the first wind damage report (Table 4).

\section{In situ measurements}

\section{a. Fixed and mobile mesonets}

The mobile mesonet MM1 measured decreasing temperatures on its northbound Leg 1 before 0400 UTC (Fig. 12) as it transected the cool side of the stationary front (Fig. 1) in the preconvective nocturnal BL (Fig. 6).
Turning west after 0400 UTC (Fig. 7), MM1 subsequently transects the weak, linear MCS. Rapid, episodic temperature decreases between 0400 and 0430 UTC are associated with MM1 transecting individual convective cores within the developing CL (e.g., Figs. 12c,d). A peak $-3^{\circ} \mathrm{C}$ temperature difference is measured between the pre-MCS environment $\left(22.5^{\circ} \mathrm{C}\right)$ and the minimum 


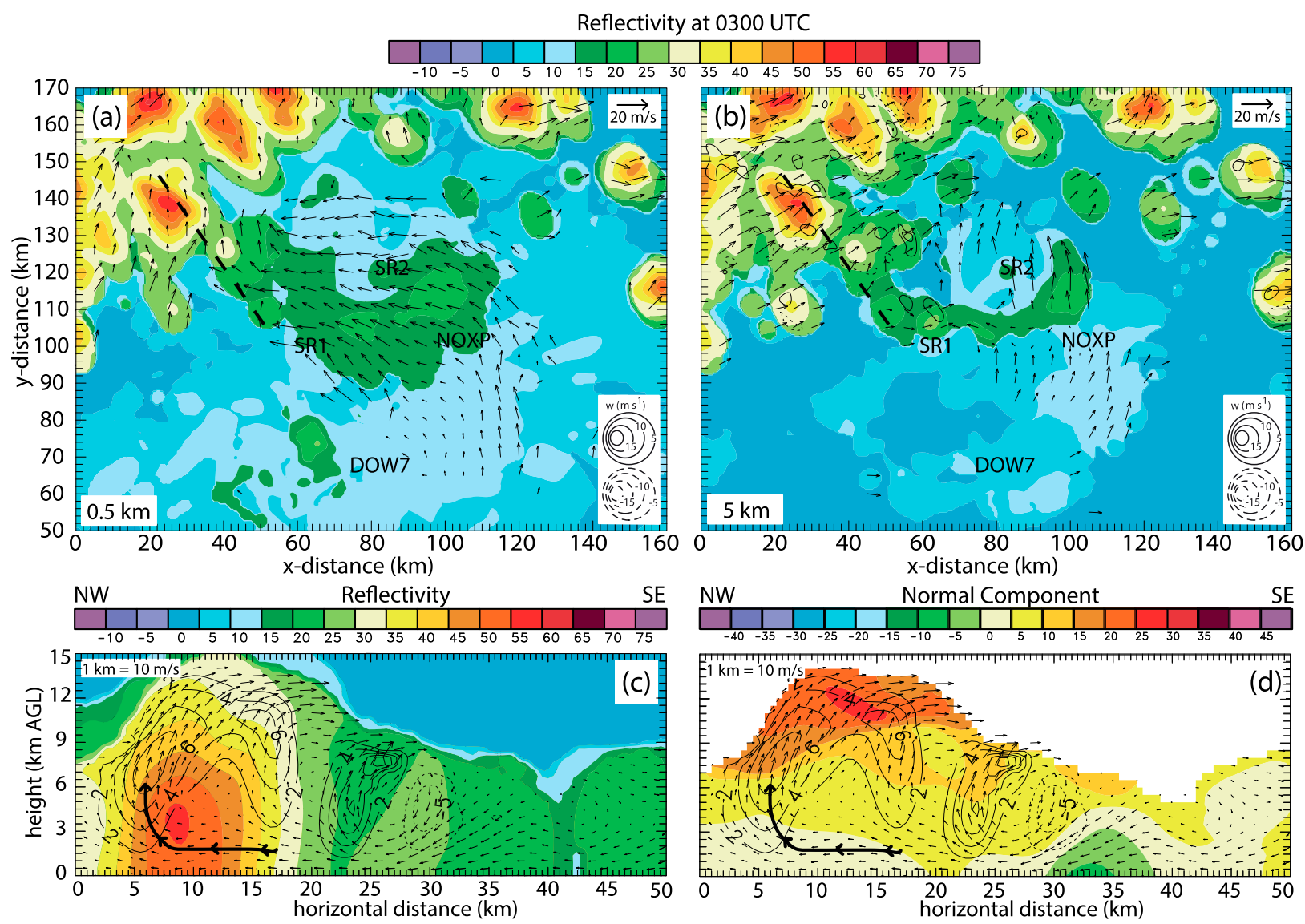

FIG. 6. Radar analysis employing up to five radars (Table 1) at 0300 UTC. (a) $0.5 \mathrm{~km}$ level analysis, (b) $5 \mathrm{~km}$ level analysis, (c) vertical cross section, and (d) vertical cross section with color-filled normal wind component. All have vector winds plotted and (a)-(c) have dBZ values color filled. The dashed black lines in (a),(b) denote the location of the cross section in (c),(d). (a),(b) Updrafts (downdrafts) contoured with solid (dashed) lines every $5 \mathrm{~m} \mathrm{~s}^{-1}$ with (c),(d) every $2 \mathrm{~m} \mathrm{~s}^{-1}$ are shown. Thick black lines in (c),(d) indicate backward trajectories ending at the arrow head. All radar locations are labeled with the exception of KTWX since it was further south in the domain. All vectors are ground-relative winds in the sectional plane, with scaling factor and contour intervals located in the upper right corner and lower right corner, respectively.

storm-scale cold pool $\left(19.5^{\circ} \mathrm{C}\right)$ around 0420 UTC within a developing intrusion of deep RTF flow entering the proximate $55 \mathrm{dBZ}$ cell $10 \mathrm{~km}$ southeast of MM1 (Fig. 12d). Both radar-analyzed and MM1measured surface winds are rapidly backing from easterly to northerly during this transect around 0420 UTC (Fig. 12d vs Fig. 12b).

The mobile mesonet MM2 operated on a single north-south road throughout the deployment. The temperature increased from 0300 to 0340 UTC as MM2 headed south toward the stationary boundary, then decreased toward 0425 UTC as MM2 reversed its leg northward into the cooler air (Fig. 13a). The nearly identical temperature profiles north of the peak value from MM1 at 0300 UTC (Fig. 12a) and MM2 at 0340 UTC (Fig. 13a) are indicative of the relative stationarity of the postfrontal nocturnal BL in the 0300 0430 UTC period. A much sharper temperature decrease is noted around 0425 UTC along with a transient
$8 \mathrm{~m} \mathrm{~s}^{-1}$ peak wind speed and rapid northerly wind veering (Fig. 13b). The latter temperature drop is associated with MM2 transecting the leading edge of the CL (Figs. 13c,d). Since MM2 has penetrated a potentially baroclinically augmented rear inflow rotor that has descended to the surface and surged ahead of the CL at 0430 UTC (Figs. 13c,d), this temperature drop corresponds to the initial MM observation of the surface-based mesoscale cold pool of the MCS. The cold pool temperature change at the $\mathrm{MM} 2$ transect is about $-3^{\circ} \mathrm{C}$ relative to MM2's pre-MCS environment, in accord with the temperature drop recorded by MM1 in the earlier isolated convective cores.

The NOXP scout MM temperature at the NOXP radar site remains fairly constant until a slight increase begins around 0440 UTC as wind speed gradually increases to its peak value of $9 \mathrm{~m} \mathrm{~s}^{-1}$ around 0442 UTC, at which time the temperature begins decreasing (Fig. 14a). The wind speed maximum and temperature drop are coincident 


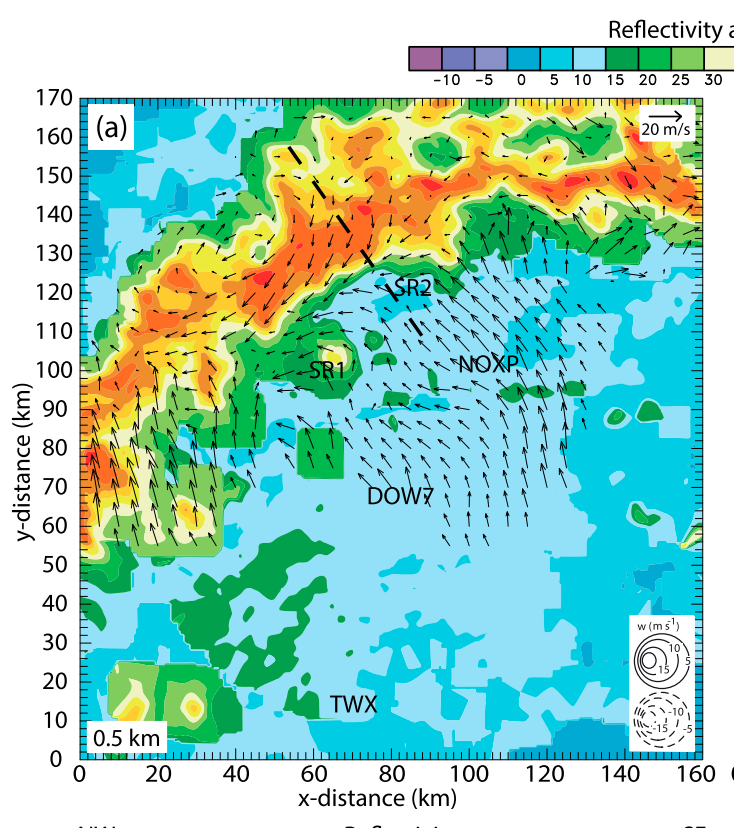

Reflectivity at 0400 UTC
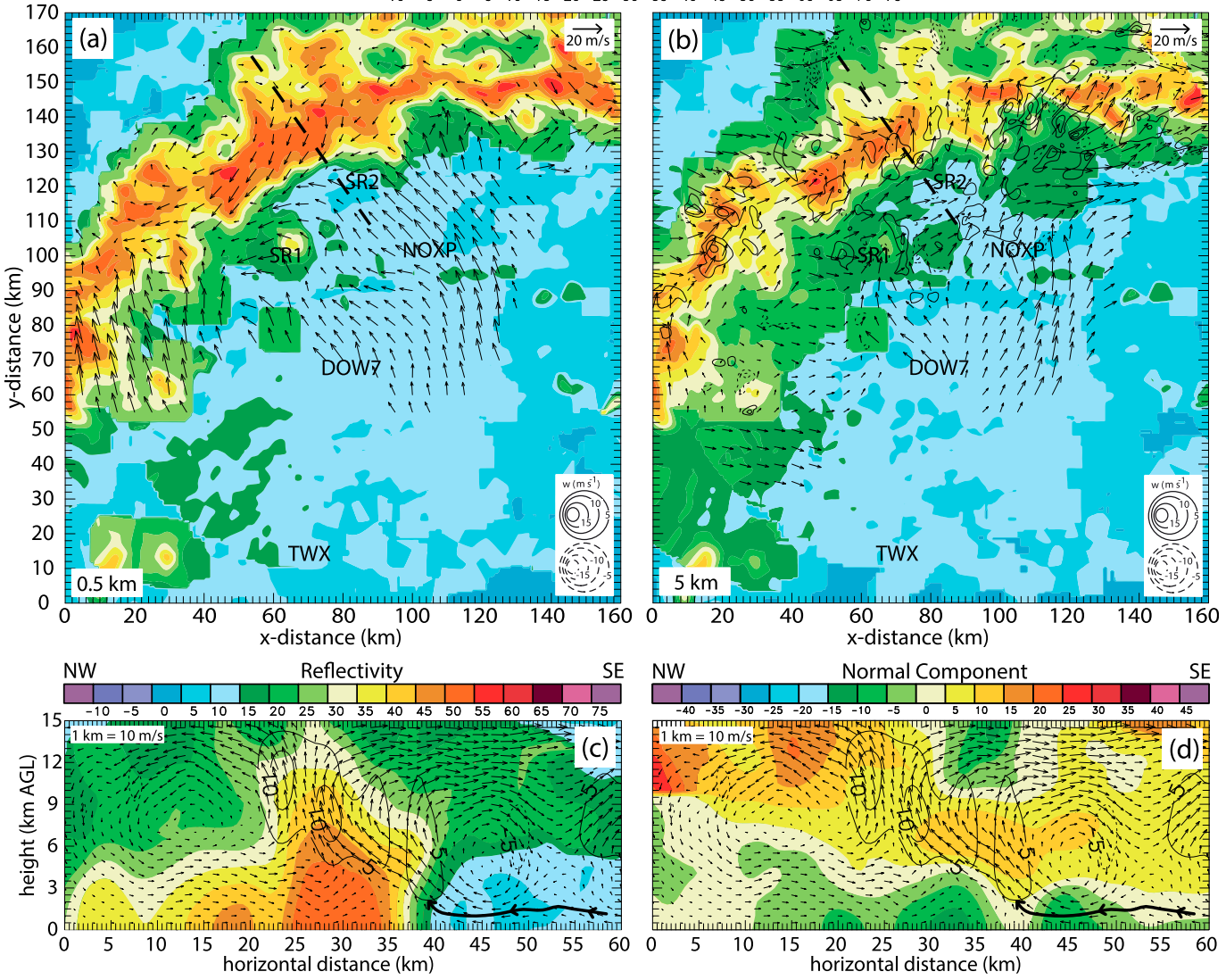

FIG. 7. Radar analysis employing up to five radars (Table 1) at 0400 UTC. (a) $0.5 \mathrm{~km}$ level analysis, (b) $5 \mathrm{~km}$ level analysis, (c) vertical cross section, and (d) vertical cross section with color-filled normal wind component. All have vector winds plotted and (a)-(c) have $\mathrm{dB} Z$ values color filled. The dashed black lines in (a),(b) denote the location of the cross section in (c),(d). Thick black lines in (c),(d) indicate backward trajectories ending at the arrow head. All radar locations are labeled and updrafts (downdrafts) are contoured in solid (dashed) lines every $5 \mathrm{~m} \mathrm{~s}^{-1}$. All vectors are ground-relative winds in the sectional plane, with scaling factor and contour intervals located in the upper right corner and lower right corner, respectively.

with the arrival of the leading edge of the mesoscale cold pool which is located within the CL. A vertical cross section of the radar analysis at 0440 UTC shows that NOXP is located at the leading edge of descending RTF flow and the reflectivity gradient (Figs. 14c,d), about 2 min before the onset of surface cooling (Fig. 14a). The analysis at 0445 UTC over NOXP, which is $3 \mathrm{~min}$ after the onset of surface cooling, shows NOXP located beneath quasihorizontal RTF flow between two reflectivity maxima deeper within the RTF flow (Figs. 14e,f). These analyses reveal an offset between the location of the leading edge of the RTF flow and the leading edge of the mesoscale cold pool, which are conventionally assumed to be collocated. It is noteworthy that compressional warming in the downdraft above NOXP at 0440 UTC would be expected to offset diabatic cooling to help produce the MM-measured warm nose feature at 0440 UTC (e.g.,
Miller 2018). Note also that by 0445 UTC, the downdraft has moved to the southeast of the NOXP site, with implied local diabatic cooling now unopposed by downdraft compressional warming (e.g., Miller 2018), thereby supporting the onset of MM-measured mesoscale outflow cooling at the NOXP site. The radar morphologies around NOXP from 0440 to 0445 UTC (Figs. 14c-f) and MM2 around 0430 UTC (Figs. 13c,d) are similarly embedded in rear inflow that is descending to the surface within the $\mathrm{CL}$, also accompanied by similar surface temperature decreases and wind speed increases (Figs. 14a,b versus Figs. 13a,b).

\section{b. Comparison of surface thermal profiles relative to mesoscale cold pool passage}

A comparison of the various fixed and mobile mesonet temperature profile observations relative to the arrival of the leading edge of the mesoscale cold pool (hereafter 

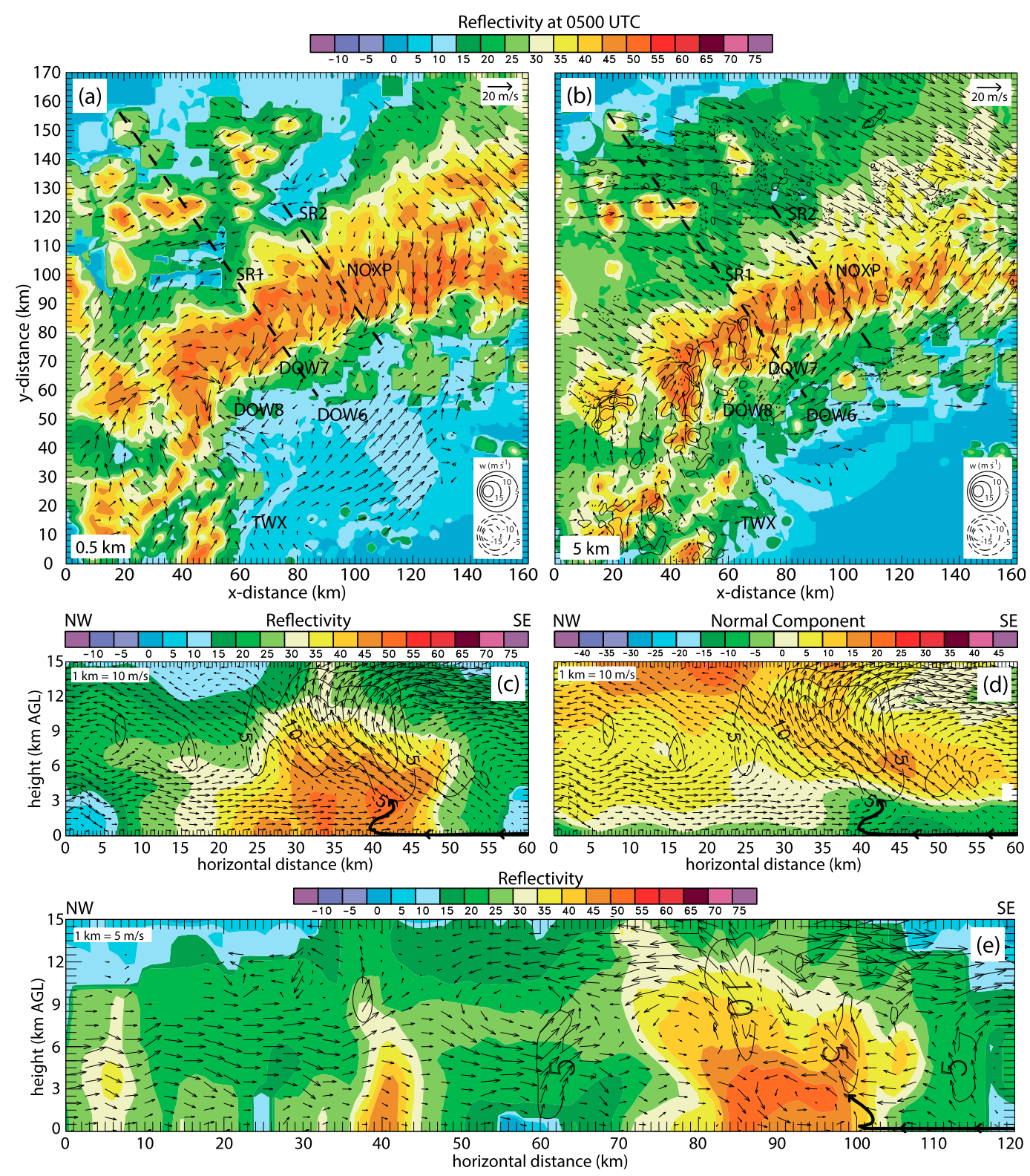

FIG. 8. Radar analysis employing up to seven radars (Table 1) at 0500 UTC. (a) $0.5 \mathrm{~km}$ level analysis, (b) $5 \mathrm{~km}$ level analysis, (c) short vertical cross section, and (d) short vertical cross section with color-filled normal wind component; (e) long vertical cross section. All have vector winds plotted and (a),(b),(c),(e) have dBZ values color-filled. The short dashed black line in (a),(b) denotes the location of the cross section in (c),(d) and the long dashed line in (a),(b) denotes the location of the cross section in (e). Thick black lines in (c)-(e) indicate backward trajectories ending at the arrow head. All radar locations are labeled and all vectors, scaling, and contour intervals are the same as in Fig. 7.

referred to as the thermodynamic outflow boundary or "TOB") provides an integrated 4-D model of the relative intensities of the mesoscale cold pool and the pre-MCS NBL (Fig. 15 versus Fig. 4). The temperature evolution of five mesonets (i.e., one mobile and four fixed) between one hour prior and one hour after the TOB passage reflects the initial stationary-frontal temperature gradient up to $1 \mathrm{~h}$ prior to TOB passage (Figs. 15a,b). The slight temperature increase measured by NOXP, MG3, and MM2 prior to
TOB passage, which is associated with the initial passage of a kinematic outflow boundary (KOB), may have been forced by some combination of local vertical mixing of the NBL associated with transient post-KOB vertical shear preceding the TOB (e.g., Doswell and Haugland 2007; Nallapareddy et al. 2011) and compressional warming in the previously noted radar-derived downdraft rotor circulations.

The rate of cooling is largest at MG3 accompanying the passage of the initial bowing MCS segment, as 

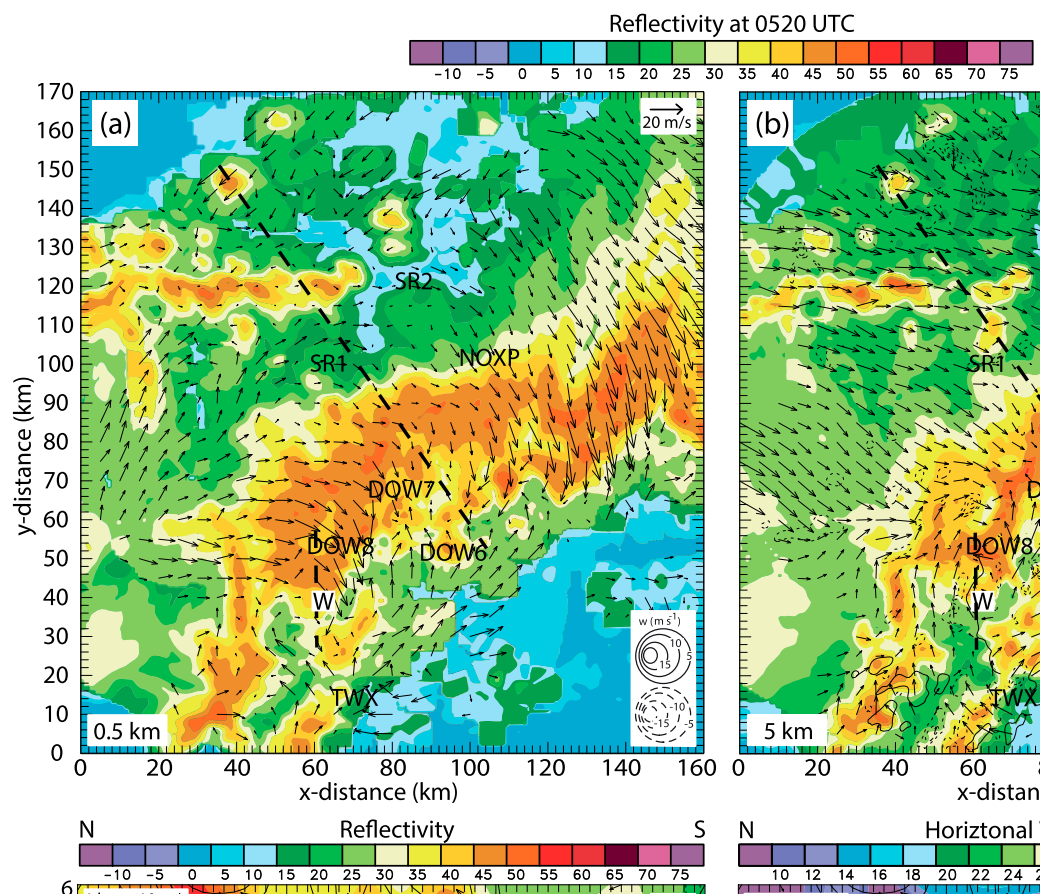

$\mathrm{N} \quad$ Horiztonal Wind Speed $(\mathrm{m} / \mathrm{s}) \quad \mathrm{S}$
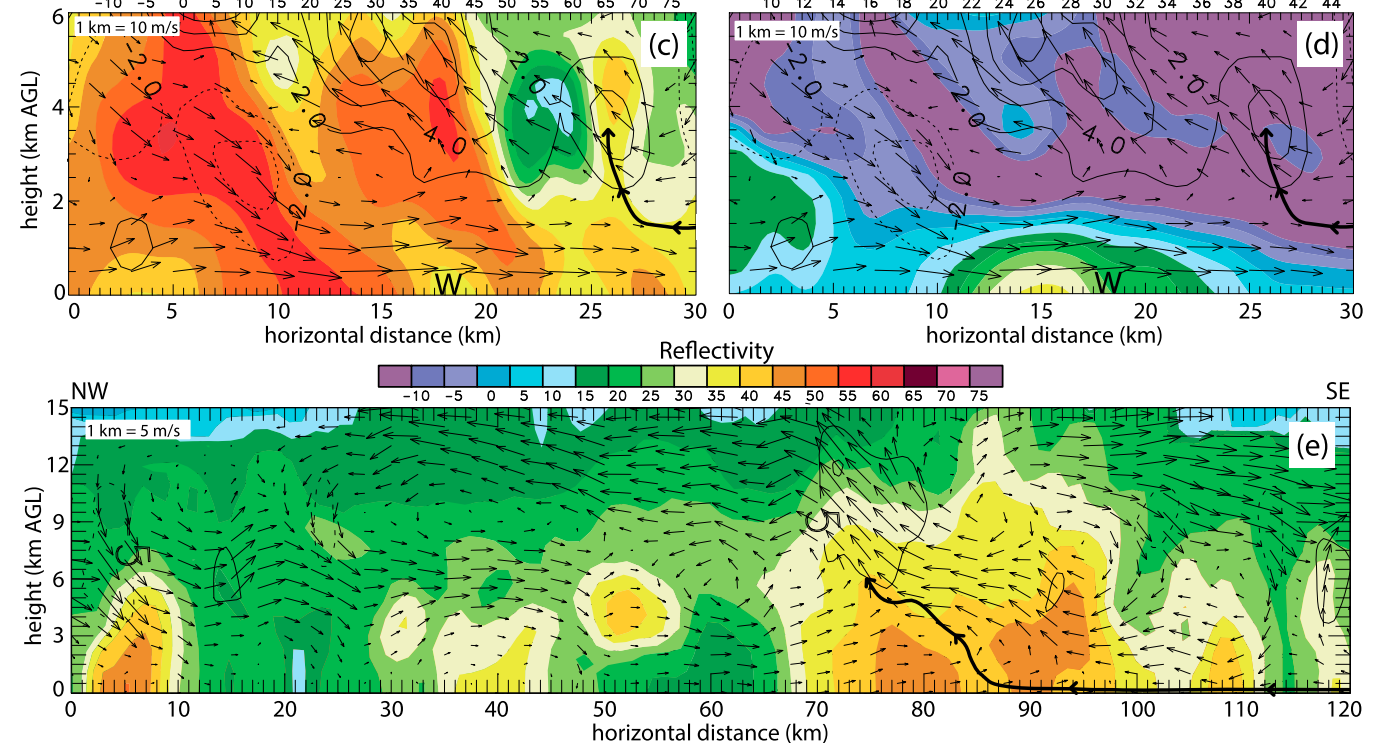

FIG. 9. Radar analysis employing up to seven radars (Table 1) at 0520 UTC. (a) Full domain, one-pass Barnes analysis at $0.5 \mathrm{~km}$ level; (b) as in (a), but at $5 \mathrm{~km}$ level; (c) north-south vertical cross section from DOW6-TWX nested-grid, two-pass Barnes analysis; (d) as in (c), but with color-filled horizontal wind speed; (e) northwestsoutheast vertical cross section of full domain, one-pass Barnes analysis. All panels include vector winds, and (a),(b),(c),(e) have color-filled reflectivity (dBZ) . The north-south-oriented dashed black line in (a),(b) denotes the location of cross section (c),(d), while the northwest-southeast-oriented dashed line in (a),(b) denotes the location of cross section (e). Thick black lines in (c)-(e) indicate backward trajectories ending in the plane of the cross section at the arrow head. The "W" denotes the relative $(x, y)$ location of the wind report at $(63,39 \mathrm{~km})$. All radar locations are labeled, and all vectors and scaling are the same as in Fig. 7. Updraft and downdraft contours in (a),(b),(e) are as in Fig. 7, while updrafts (downdrafts) in (c),(d) are contoured in solid (dashed) lines every $2 \mathrm{~m} \mathrm{~s}^{-1}$.

opposed to MG1 and NOXP which have similar but weaker temperature decreases associated with the linear MCS passage (Fig. 15). Despite the different environmental temperatures prior to MCS passage, the outflow temperature is between $19.5^{\circ}$ and $21^{\circ} \mathrm{C}$ for all mesonet surface observations. Hence, the mesoscale cold pool was rather homogeneous in time and space. The cooling rate accompanying the TOB passage is 

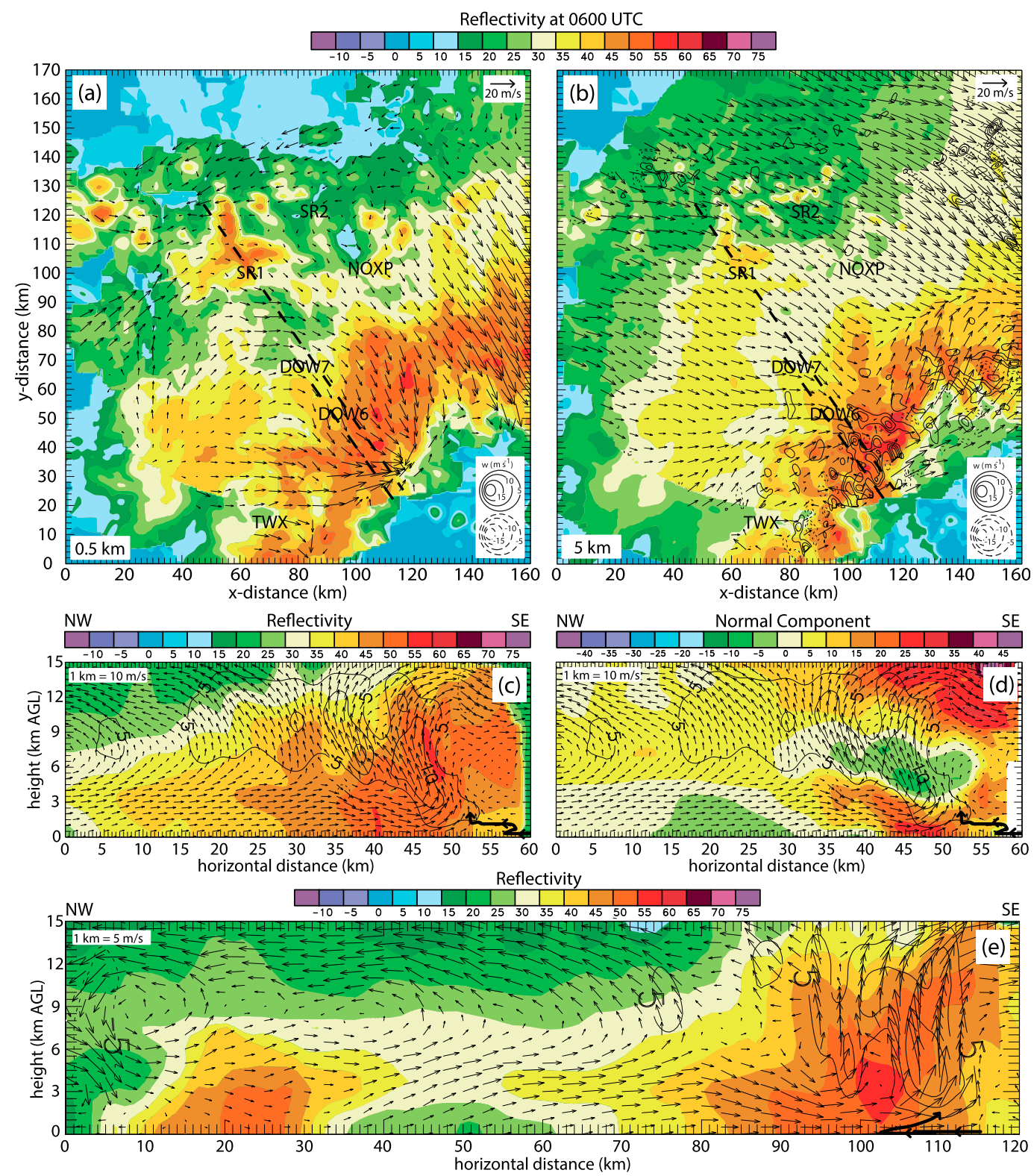

FIG. 10. Radar analysis employing up to six radars (Table 1) at 0600 UTC. (a) $0.5 \mathrm{~km}$ level analysis, (b) $5 \mathrm{~km}$ level analysis, (c) short vertical cross section, (d) short vertical cross section with color-filled normal wind component, and (e) long vertical cross section. All have vector winds plotted and (a),(b),(c),(e) have dBZ values color filled. The short dashed black line in (a),(b) denotes the location of the cross section in (c),(d) and the long dashed line in (a),(b) denotes the location of the cross section in (e). Thick black lines in (c)-(e) indicate backward trajectories ending at the arrow head. All radar locations are labeled and all vectors, scaling, and contour intervals are the same as in Fig. 7.

smaller in the linear MCS than the bowing MCS segment owing mainly to the much warmer pre-MCS environment ahead of the bowing segment south of the front. The virtual potential temperature $\left(\theta_{v}\right)$ profiles of the five mesonets have similar trends to temperature. The mesonets that experienced the TOB passage all have $\theta_{v}$ values that converge to about $23^{\circ} \mathrm{C}$, which again indicates that the cold pool was fairly homogeneous over a large spatial and temporal domain.

\section{c. H-Z sounding analysis of the MCS and its environment}

An analysis of soundings launched alternately from MG1 and MG2 at the same location over a 5-h period from 0215 to 0702 UTC spans the pre-MCS through 

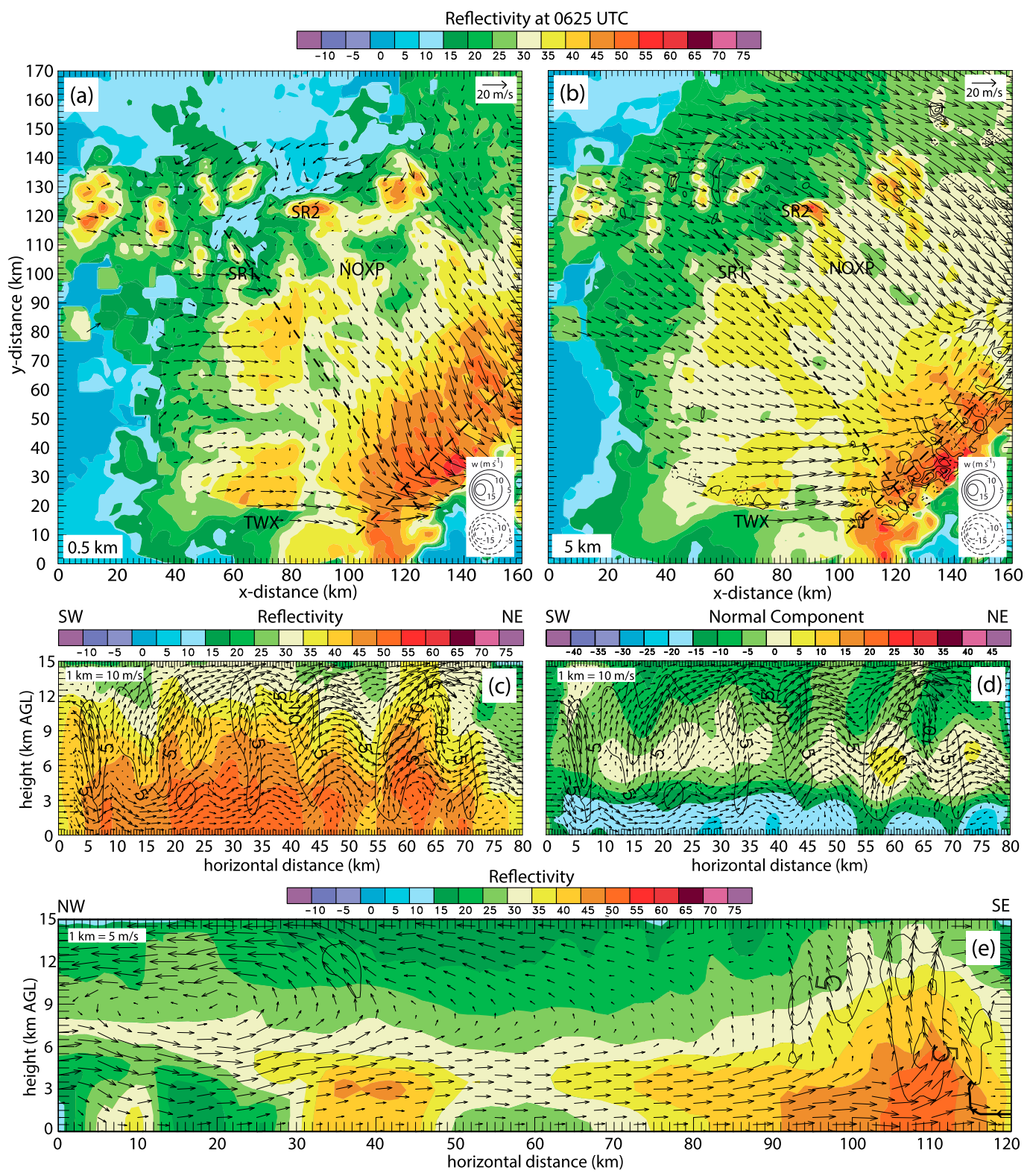

FIG. 11. Radar analysis employing up to four radars (Table 1) at 0625 UTC. (a) $0.5 \mathrm{~km}$ level analysis, (b) $5 \mathrm{~km}$ level analysis, (c) short vertical cross section, (d) short vertical cross section with color-filled normal wind component, and (e) long vertical cross section. All have vector winds plotted and (a),(b),(c),(e) have dBZ values color filled. The short dashed black line in (a),(b) denotes the location of the cross section in (c), (d) and the long dashed line in (a),(b) denotes the location of the cross section in (e). Thick black line in (e) indicates backward trajectories ending at the arrow head. All radar locations are labeled and all vectors, scaling, and contour intervals are the same as in Fig. 7.

post-MCS mesoscale environments (Fig. 16). Weak ascent begins around 0347 UTC $\left(0.25 \mathrm{~m} \mathrm{~s}^{-1}\right)$, over an hour prior to MCS passage, and increases in magnitude to approximately $1 \mathrm{~m} \mathrm{~s}^{-1}$ at $1 \mathrm{~km}$ as an elevated maximum just above the elevated residual layer. The magnitude of this ascent is slightly larger than the values noted to the south of MG1 in the sounding analysis across the stationary front at 0300 UTC (Fig. 2), although the preMCS ascent at MG1-MG2 in Fig. 16 begins almost $1 \mathrm{~h}$ after the $Y-Z$ analysis in Fig. 2. The mesoscale ascent increases to about $5 \mathrm{~m} \mathrm{~s}^{-1}$ within the $\mathrm{CL}$ zone, followed by a $1 \mathrm{~m} \mathrm{~s}^{-1}$ mesoscale downdraft forced by converging elevated rear inflow after the radar-analyzed KOB passage around 0520 UTC ( $x=0 \mathrm{~km}$ in Fig. 16). 

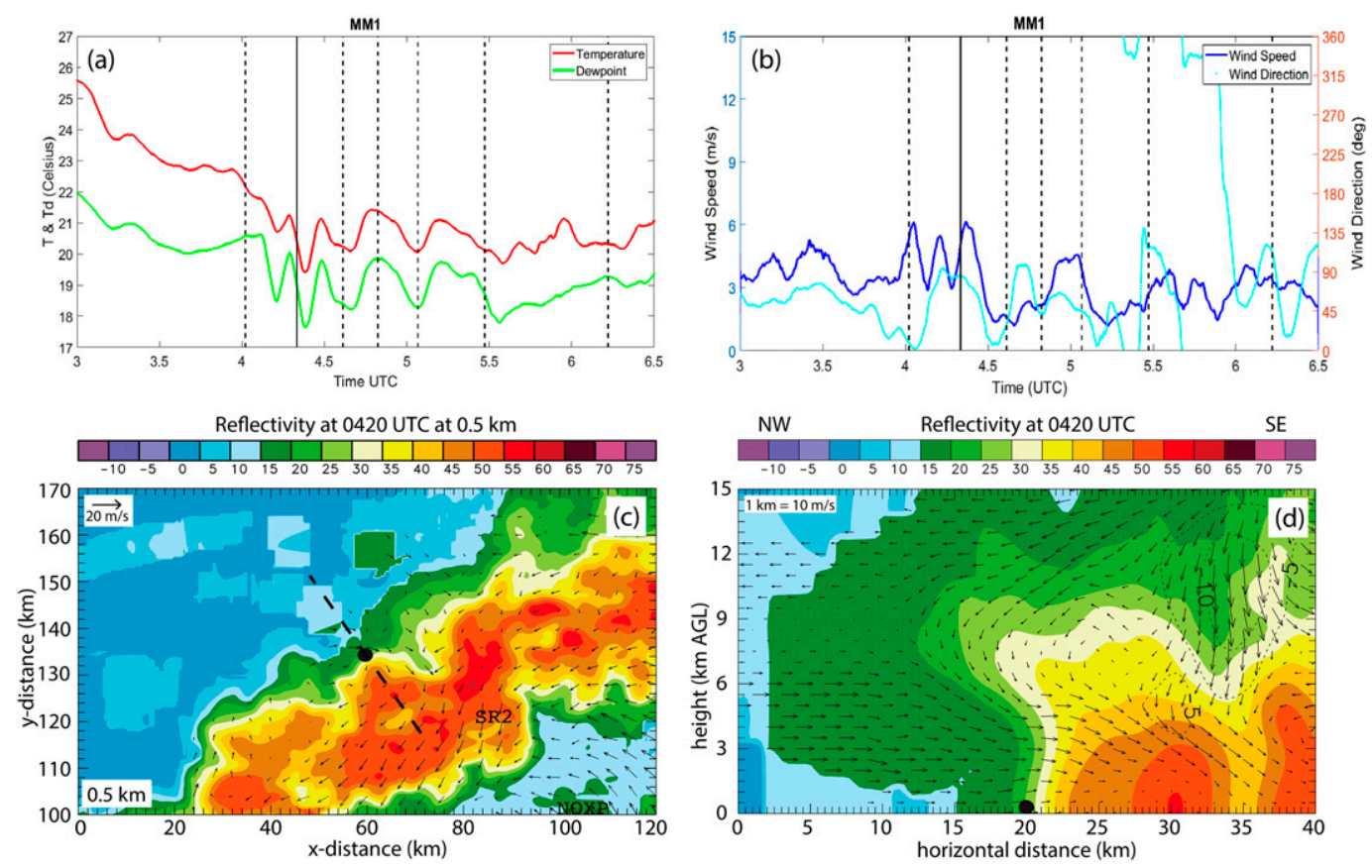

FIG. 12. In situ observations from MM1 in context of local radar-analyzed MCS morphology. (a) temperature (red) and dewpoint (green), (b) wind speed (dark blue) in $\mathrm{m} \mathrm{s}^{-1}$ and wind direction (light blue) in degrees, (c) $0.5 \mathrm{~km}$ analysis over MM1 (black dot) with dashed black line to denote the location of (d), and (d) colorfilled reflectivity with wind vectors plotted in a northwest-southeast-oriented cross section over MM1 (black dot) at 0420 UTC. Data in (a),(b) were recorded by MM1 as it moved through the MCS environment from 0300 to 0630 UTC. The vertical dashed lines indicate times when MM1 changed directions. MM1 drove north for leg 1, turned west at 0400 UTC and headed west for leg 2, headed south for leg 3, headed east for leg 4, headed south for leg 5 , headed southeast for leg 6 , and finally headed west for leg 7 . The solid vertical line indicates the time of the radar analysis in (c),(d). Contours for updrafts and downdrafts in (c),(d) are the same as in Fig. 7.

The MG2 mesonet measurements of sharply decreasing $q_{v}$ and $\theta_{v}^{\prime}$ values reveal the coincidence of the KOB and TOB associated with passage of the leading edge of the surface-based mesoscale cold pool at the sounding launch location (Figs. 16a,b). Decreasing $q_{v}$ and $\theta_{v}^{\prime}$ in the $0.5-1.5 \mathrm{~km}$ layer up to $30 \mathrm{~km}$ ahead of the TOB coincides with the onset of the weak pre-MCS ascent (Figs. 16a,b). The double-minimum of $\theta_{v}^{\prime}$ within the lowest $0.5 \mathrm{~km}$ and the $0.5-2 \mathrm{~km}$ layers (Fig. 16b) reflects both the initial strongly stratified base-state profile around 0200 UTC and the fully 3D air trajectories that feed these distinct layers from outside the cross section. Positively perturbed $q_{v}$ and $\theta_{v}^{\prime}$ values in the mesoscale updraft from 3 to $12 \mathrm{~km}$ reflect the combined effects of vertical transport and divergent outflow of warm, moist air into the anvil combined with diabatic heating associated with cloud and precipitation formation in the CL and TS region (Rutledge et al. 1988). Decreasing $q_{v}$ values are noted within the $0-4 \mathrm{~km}$ layer of drier rear inflow and mesoscale subsidence at the leading edge of the TS region.
The warmest air in advance of the MCS in $\theta_{e}$ (Fig. 16c) and $\theta_{w}$ (Fig. 16d) resides within the $0.5-2 \mathrm{~km}$ postfrontal ERL (Fig. 2). Strong westerly shear (Fig. 16e) entering the cross-sectional plane (i.e., nonslabular flow) in the $0-2 \mathrm{~km}$ layer likely offsets localized ERL lifting of warm, moist air, while midlevel westerly shear combined with the absence of convective-core soundings results in relative midlevel minima of $\theta_{e}$ and $\theta_{w}$. The onset of weak ascent both cools and lifts the nose of the warm ERL. Thus, the MCS inflow arriving from south of the front is cooled and lifted from the combined mesoscale ascent in the frontal boundary followed by ascent in the ERL. Although the magnitudes of the frontal and ERL lifting are rather small, they both act on low-end meso- $\beta$ length scales $(20-200 \mathrm{~km})$ and thus have a significant timeintegrated impact on priming the pre-MCS environment to support deep, moist convection. It should be noted that a nocturnal inversion is maintained despite the ERL cooling, indicating that the MCS's inflow environment is stable in low levels throughout its lifetime. Quasi-hydrostatic perturbation pressure forces (e.g., as inferred from Fig. 16f) would be expected to assist in 

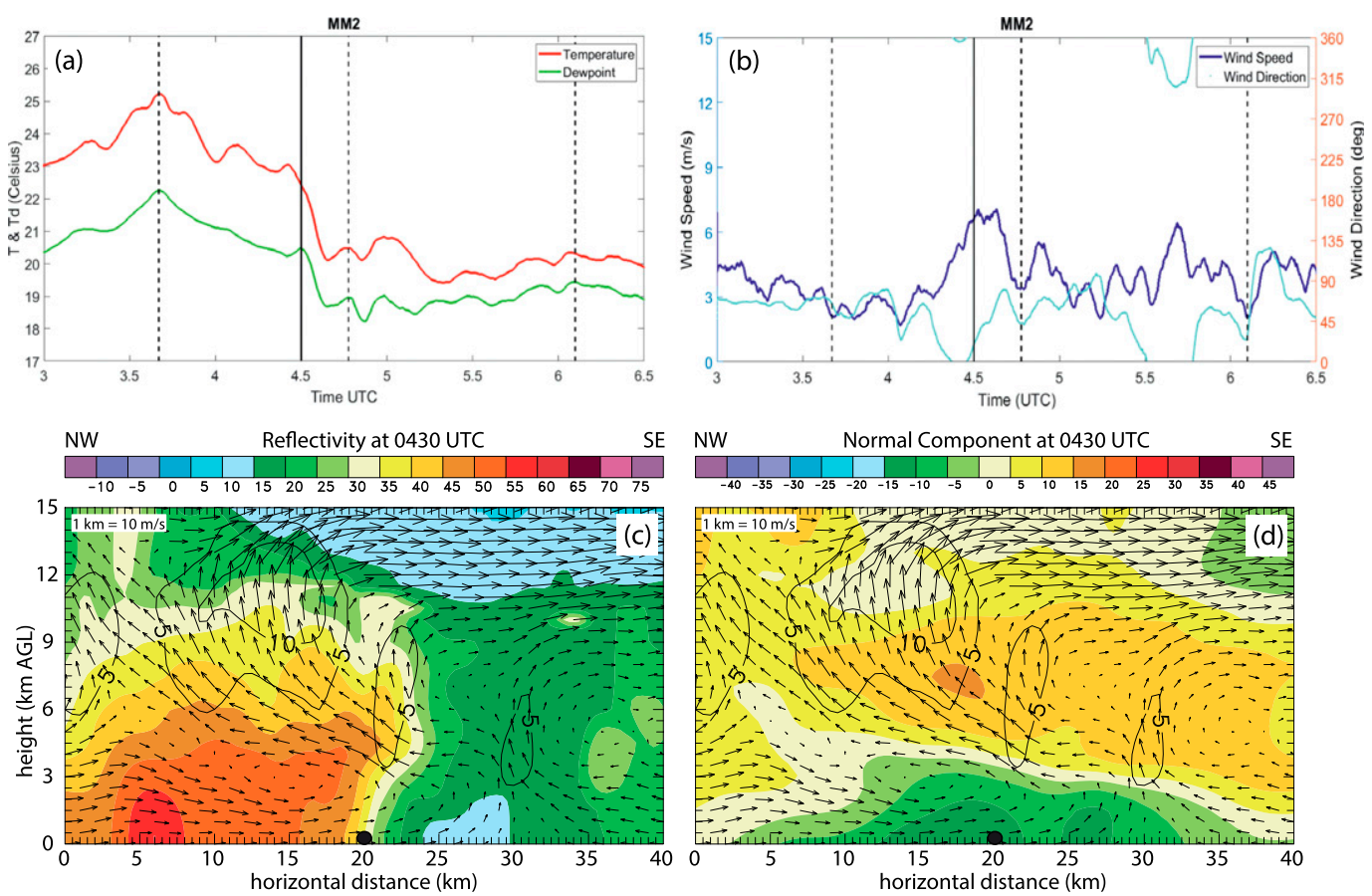

FIG. 13. In situ observations from MM2 in context of local radar-analyzed MCS morphology. (a) temperature (red) and dewpoint (green), (b) wind speed (dark blue) in $\mathrm{m} \mathrm{s}^{-1}$ and wind direction (light blue) in degrees, (c) colorfilled reflectivity with wind vectors plotted in a northwest to southeast oriented cross section over MM2 (black dot) at 0430 UTC, and (d) vertical cross section in (c) with color-filled normal wind component. Data in (a),(b) were recorded by MM2 as it drove around the MCS environment from 0300 to 0630 UTC. The vertical dashed lines indicate that the mesonet changed directions. MM2 drove south for leg 1, north for leg 2, south for leg 3, and southeast for leg 4 . The solid line indicates the time of the radar analysis in (c),(d). In (c),(d), contours for updrafts and downdrafts are the same as in Fig. 7.

generating the sounding-analyzed low-level horizontal convergence and upper-level divergence, while decelerating the mesoscale rear inflow into the rear downdraft (e.g., Braun and Houze 1994; Smull and Houze 1987).

\section{Discussion}

\section{a. The CI process in the pre-MCS environment}

Elevated nocturnal CI frequently occurs on the north side of an east-west stationary front due to frontally forced mesoscale ascent and warm air advection (Zheng et al. 1995; Jirak and Cotton 2007; Coniglio et al. 2010; Wetzel et al. 1983; Maddox 1980, 1983; Johns and Hirt 1987; Trier et al. 2011; Trier and Parsons 1993; Gale et al. 2002). Although a weak LLJ that satisfies the Bonner (1968) "Criterion 1" was present in the 0430 UTC MG3 sounding (not shown) to further enhance confluence, the meridional mesoscale lifting and transport of warm air over the front was nevertheless an important factor in the elevated CI event. These initial cells were based between the $1 \mathrm{~km}$ AGL capping layer and a near-saturated layer around $3 \mathrm{~km}$ AGL that was in the process of forming between 0215 and 0300 UTC (Fig. 3).
It is hypothesized that the CI around 0230 UTC reflects the layer lifting and saturation of air around $2 \mathrm{~km}$ AGL where environmental horizontal winds (Fig. 3) had roughly the same orientation as the initiated $\mathrm{CL}\left(\sim 60^{\circ}\right.$ from North; Fig. 1). More specifically, it is further hypothesized that the $\mathrm{CI}$ event has been preferentially forced by persistent mesoscale frontal lifting owing to the favorable alignment of the front with the inferred environmental LFC-level winds via a process of transport-lifting with spatially (temporally) lagged convective destabilization (e.g., Peters et al. 2017). The hypothesized lifted moist BL trajectories initially ascend above the sloping frontal surface toward the northwest, and ultimately veer to the northeast and form a cloud band in the sheared flow similarly to the CI process along drylines (Ziegler et al. 1997; Ziegler and Rasmussen 1998). The 0304 UTC MG3 sounding was layer-lifted following the 1.5-D kinematic method of Ziegler et al. (2010) and Wade et al. (2018) to test this hypothesis (Fig. 17). The nocturnal BL and the warm, dry ERL in the lowest $3 \mathrm{~km}$ of the 0304 UTC MG3 sounding (Fig. 17a) are substantially cooled and moistened via about $80 \mathrm{~min}$ of layer lifting assuming an updraft in the lowest $3 \mathrm{~km}$ with a maximum value of $0.5 \mathrm{~m} \mathrm{~s}^{-1}$ at $1 \mathrm{~km}$ 

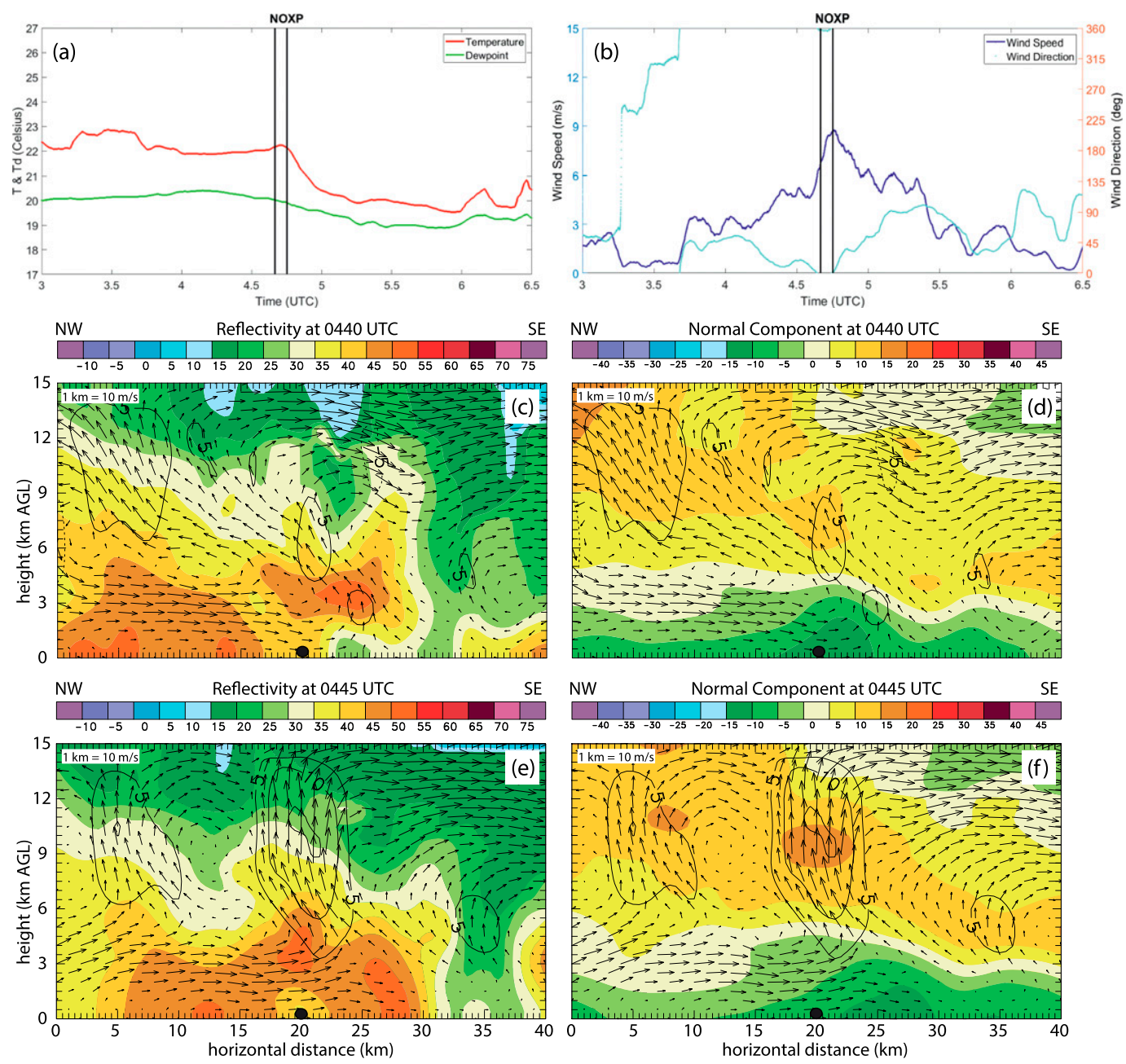

FIG. 14. In situ observations from NOXP Scout mobile mesonet (MMS) in context of local radar-analyzed MCS morphology. (a) MMS temperature (red) and dewpoint (green), (b) MMS wind speed (dark blue) in m s ${ }^{-1}$ and wind direction (light blue) in degrees, (c) color-filled reflectivity with wind vectors plotted in a northwest to southeast oriented cross section over NOXP (black dot) at 0440 UTC, and (d) vertical cross section as in (c) with color-filled normal wind component. Data in (a),(b) were recorded at the fixed NOXP site in the MCS environment from 0300 to 0630 UTC. The solid vertical lines in (a),(b) indicates the times of the radar analyses in (c),(d) and (e),(f). Contours for updrafts and downdrafts in (c)-(f) are as in Fig. 7. Note that the NOXP Scout was mobile between 0300 and 0345 UTC, and was stationary after 0345 UTC.

AGL (Fig. 17b). A cloudy, moist absolutely unstable layer (MAUL) forms above $1.9 \mathrm{~km}$ around the top of the lifted layer (Fig. 17b). The ability of mesoscale frontal layer lifting to form an elevated cloudy, MAUL-bearing layer would be expected to increase the probability of elevated $\mathrm{CI}$ and is consistent with the observed CI event in this case.

\section{b. Kinematic aspects of the elevated to surface-based MCS transition}

The cumulative presented kinematic analyses of 3D radar airflow evolution (Figs. 6-14) are visually suggestive of initially mainly elevated, isolated CL cells with localized surface-based downdrafts and somewhat elevated updraft inflows during the period from about 0300 to 0400 UTC. The descending base elevation of system-wide values of updraft volume and updraft mass flux exceeding $140 \mathrm{~km}^{3}$ and $120 \mathrm{~kg} \mathrm{~s}^{-1}$, respectively, from 2 to about $1 \mathrm{~km}$ during the period $0300-0415$ UTC (Figs. 5b,c) lends further support to the implied descent of the base updraft inflow level during this early period.

A detailed kinematic analysis of updraft backward trajectory origin levels provides further insight regarding the characterization of convective updraft source layers to augment the previously discussed individual updraft-inflow trajectories (Fig. 18). The overall number of backward updraft-inflow trajectories increases from 

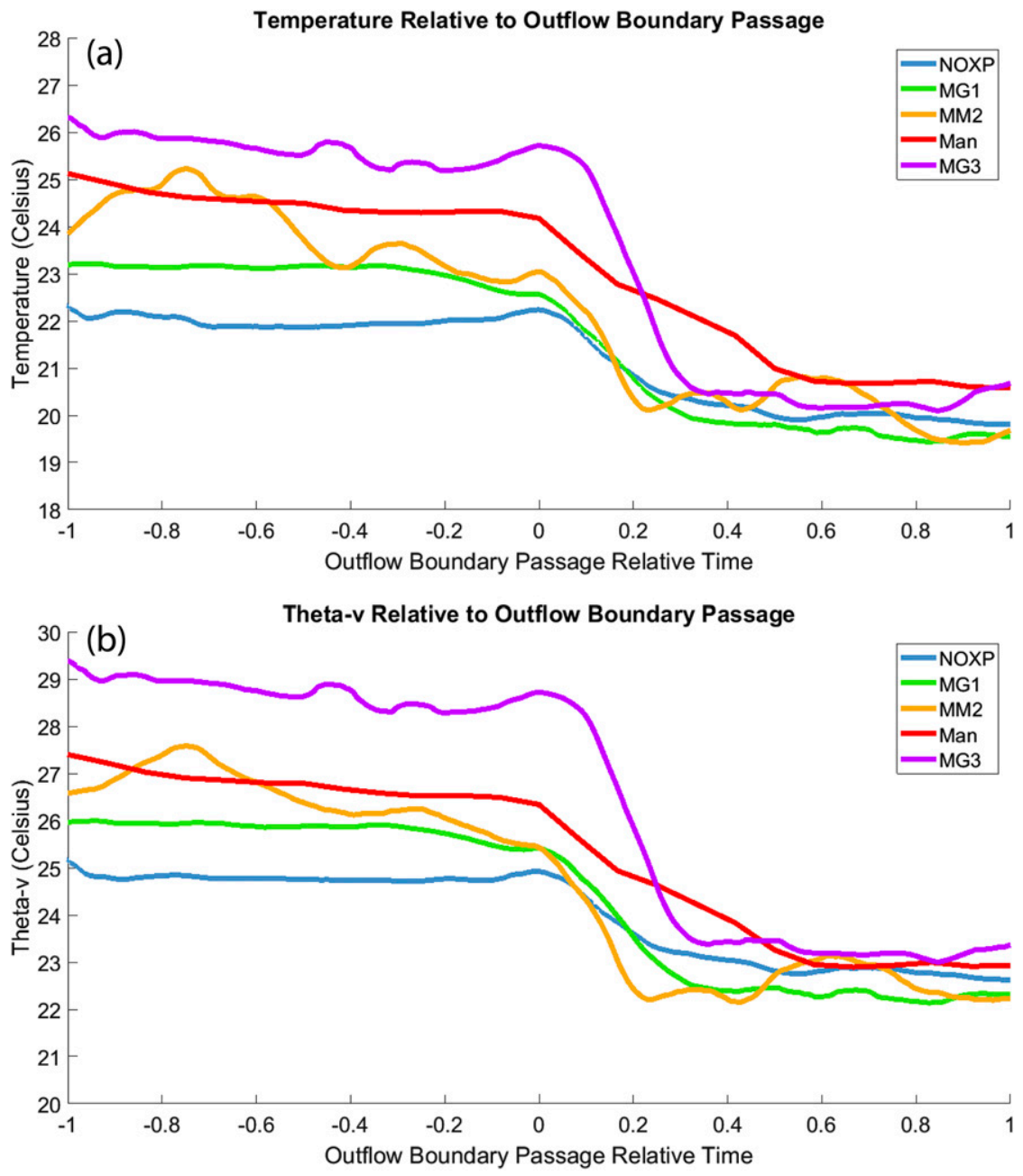

FIG. 15. Temperature variables one hour before outflow boundary passage to one hour after outflow boundary passage. (a) Temperature $\left({ }^{\circ} \mathrm{C}\right)$; (b) $\theta_{v}\left({ }^{\circ} \mathrm{C}\right)$. The 0 indicates the time of outflow boundary passage for each platform that experienced a temperature drop. Lines are plotted for MG1 (green), MG3 (purple), NOXP (light blue), MM2 (orange), and Manhattan (red).

0400 to 0600 UTC as the number and volumetric coverage of convective updrafts in the intensifying MCS increase, as supported by increasing horizontally integrated updraft mass fluxes at steadily decreasing base elevations (Fig. 18a). The lowest number of updraft inflow trajectories (almost all originating from above $\sim 0.5-1 \mathrm{~km}$ ) occur during the first $30 \mathrm{~min}$, while the bulk of updraft trajectories originate from throughout the lowest $4 \mathrm{~km}$ after 0330 UTC (Fig. 18a). Updraft inflow trajectories originate mainly from the lowest $2.5 \mathrm{~km}$ after 0430 UTC. Beginning around 0440 UTC (when the initial bowing outflow segment and the surface-based mesoscale cold pool are first observed) and particularly from 0500 to 0600 UTC, the largest single-layer concentration of inflow trajectories is generally from within the lowest $0.5-1 \mathrm{~km}$. It is hypothesized that the pronounced increase in trajectories from lower levels arises from some combination of forced lifting from the mesoscale thermal solenoid and vertical perturbation pressure forces within CL cell updrafts (e.g., Billings and Parker 2012).

Another trajectory analysis of the source layers of near-surface downdrafts shows that most of the downdraft air parcels originate from within the lowest $0.5 \mathrm{~km}$ layer for the entire time period (Fig. 18b). Additional downdraft air parcels from higher levels $(0.5-2 \mathrm{~km})$ are transported down into the lowest $0.5 \mathrm{~km}$ layer after 0450 UTC, due to contribution by localized strong convective downdrafts as the leading CL intensifies.

Based on kinematic observations alone in the period from 0300 (Fig. 6) to 0400 (Fig. 7) to 0500 UTC (Fig. 8), the formation and eventual onset of a descending, surface-based RTF branch between 0400 and 0500 UTC 

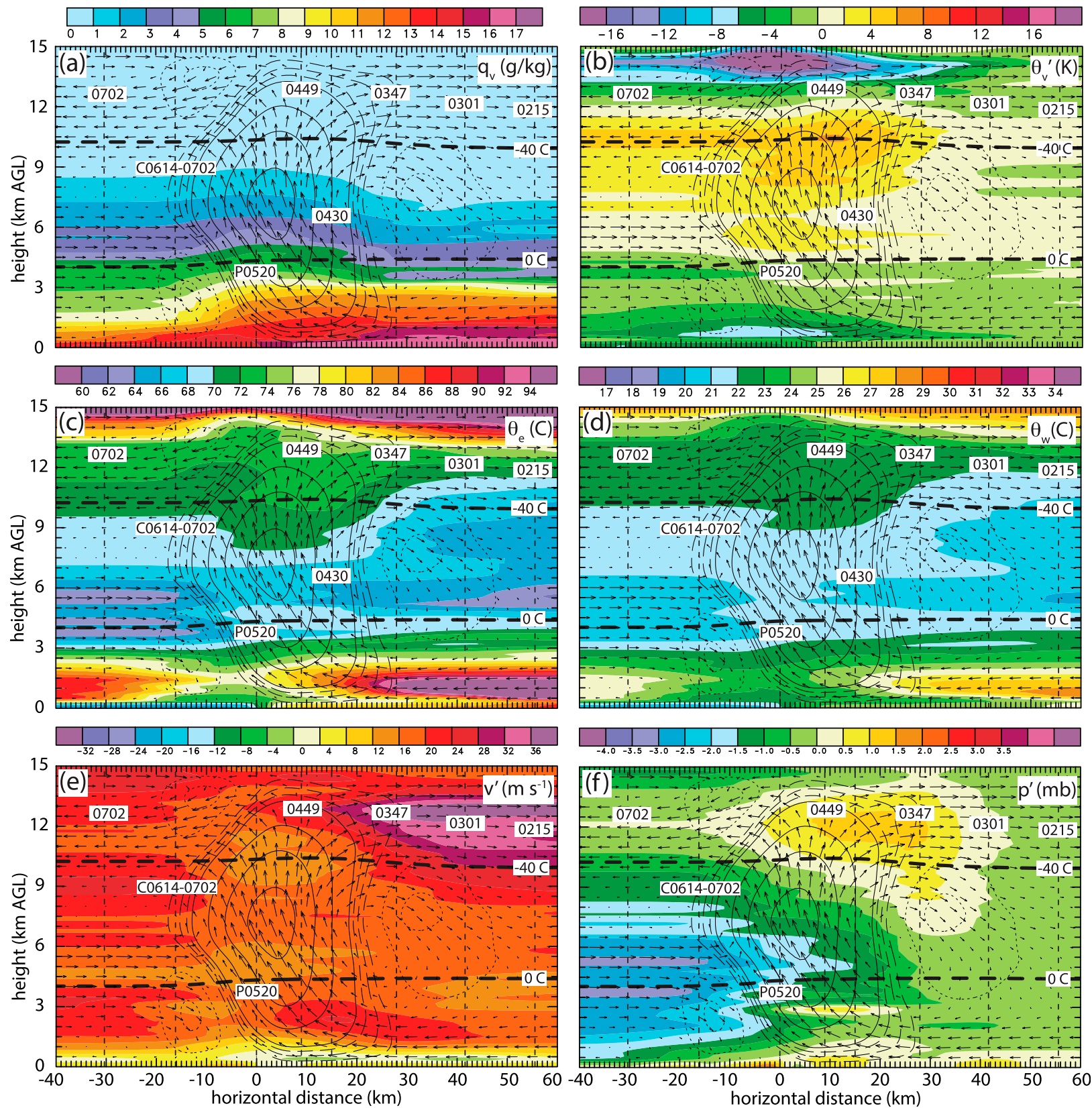

FIG. 16. Sounding analysis through MG1/MG2 location revealing environmental changes before, during, and after MCS passage. Contours are as follows: solid line is for 1 and above with $1 \mathrm{~m} \mathrm{~s}^{-1}$ intervals, the long dash is from 0.25 to $0.75 \mathrm{~m} \mathrm{~s}^{-1}$ with $0.25 \mathrm{~m} \mathrm{~s}^{-1}$ intervals, and the dotted line is from -2 to $-0.5 \mathrm{~m} \mathrm{~s}^{-1}$ at $0.5 \mathrm{~m} \mathrm{~s}^{-1}$ intervals. The six panels show the following fields: (a) $q_{v}$, (b) $\theta_{v}^{\prime}$, (c) $\theta_{e}$, (d) $\theta_{w}$, (e) $v^{\prime}$, and (f) $p^{\prime} . X=0 \mathrm{~km}$ indicates the location of the outflow boundary passage with distance calculated by assuming an MCS speed of $5 \mathrm{~m} \mathrm{~s}^{-1}$. Individual soundings are indicated by vertical dashed lines and are labeled with the time of launch. P0520 is a sounding generated by the DLA since there was no sounding launched in the convective line. C0614-0702 is the sounding launched at 0614 UTC that terminated early so the upper levels of 0702 UTC were added to the top to make a full sounding. Vectors are ground-relative airflow in the cross-sectional plane, and are scaled relative to $2 \mathrm{~km}=10 \mathrm{~m} \mathrm{~s}^{-1}$.

indicates that the linear MCS has developed a surfacebased cold pool after 0400 UTC. Analyses of mobile mesonet temperatures (Figs. 4 and 12-15) and sounding thermal variables (Figs. 16b-d) further support the hypothesized surface-based cold pool after 0400 UTC.
Following inspection of individual air trajectories from the inflow into the FTR branch (not shown), it appears that air from the lowest $1 \mathrm{~km}$ is transported into the FTR flow with some inflow parcels entering CL updrafts. If "surface-based" connotates the ingestion of air from the 

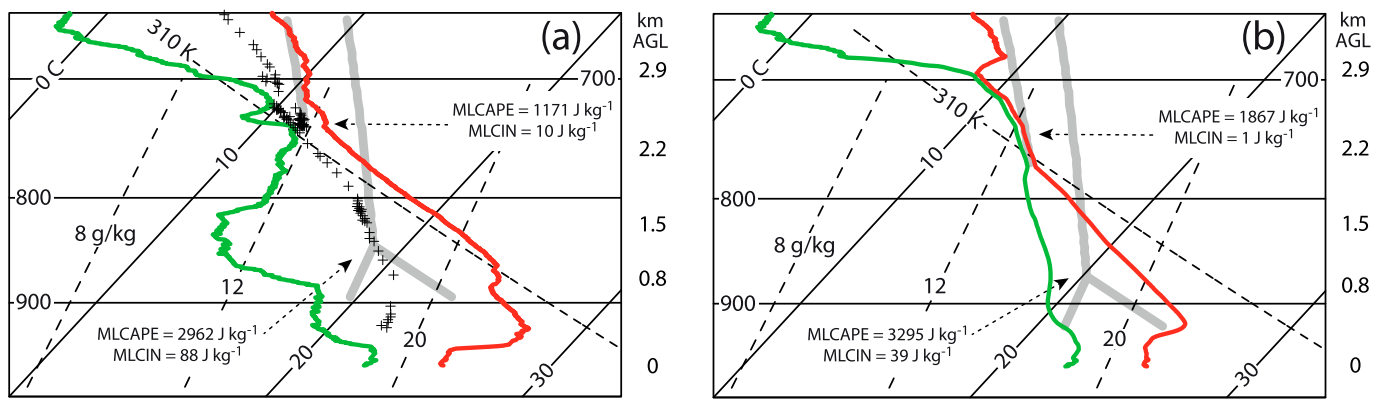

FIG. 17. Soundings related to the initiation of the 26 Jun 2015 convective line. (a) 0304 UTC MG3 sounding assumed to represent the prefrontal, warm sector environment; (b) lifted 0304 UTC MG3 sounding. The small black plus signs in (a) are saturation points (SP) of the sounding (Betts 1984). Layer-averaged values of MLCAPE and MLCIN from the surface-based layer and the top of the elevated residual layer are indicated in (a),(b) for the unlifted and lifted sounding, respectively.

surface-based NBL, the implied surface-based cold pool and the dynamic entrainment of NBL parcels into CL updrafts would indicate that the CL updrafts and the mesoscale and convective-scale downdrafts of the MCS are all surface based. However, it is important to note that the CL updrafts are fed by parcels originating from multiple levels from within the forward and rear inflows (Fig. 18a), lending support to applying the hypothesis of Corfidi et al. (2008) that a continuum of combined MCS surface-based and elevated inflow contributions are acting in the 26 June MCS.

\section{c. Kinematic and reflectivity evolution in relation to inferred MCS dynamical processes}

The combination of radar kinematics with mesonetobserved surface-based cold pool formation (Figs. 4 and 12-15) and sounding-inferred mesoscale low-level cooling associated with MCS passage (Fig. 16) suggest that the CL had developed localized surface-based convective cold pools by 0400 UTC that subsequently merged upscale to form a surface-based mesoscale cold pool from about 0430 UTC through the end of the analysis period at 0625 UTC. The rotor-like kinematic structure of the layer between the RTF and FTR branches and generation of deep convergence at the KOB location further imply the hypothesized persistent action of a thermal solenoid associated with the surface-based mesoscale cold pool after 0430 UTC. These storm- and mesoscale cold pools are hypothesized to have been driven by intensifying peak reflectivities (Fig. 5) and implied precipitation contents, that in turn stimulated increasing magnitudes of diabatic cooling from combined microphysical processes including graupel-hail melting and rain evaporation (e.g., Ziegler 2013a; DiGangi et al. 2016; Miller 2018).
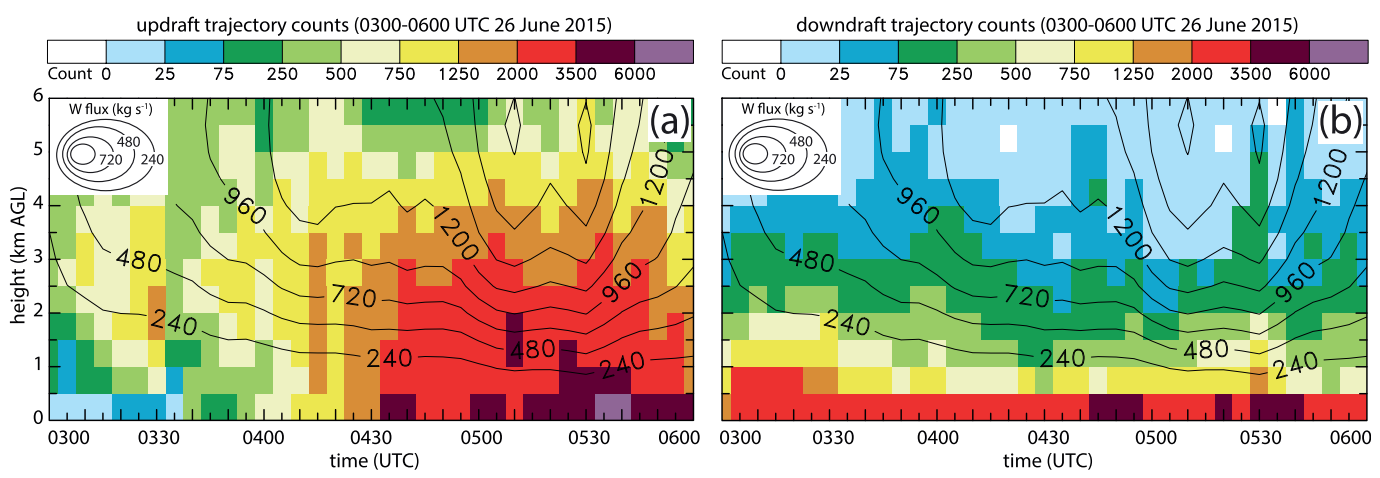

FIG. 18. Histogram frequencies of updraft and downdraft inflow trajectory origin levels in the far environment, plotted as time (UTC) vs height (km AGL) for the period 0300-0600 UTC in the 26 Jun 2015 MCS analysis. (a) Trajectories ending in updraft $>5 \mathrm{~m} \mathrm{~s}^{-1}$ and reflectivity $>35 \mathrm{dBZ}$ in the $2.5-6 \mathrm{~km}$ layer (i.e., from approximately the local inflow parcel LFC upward); (b) trajectories ending in downdraft either $<-0.5 \mathrm{~m} \mathrm{~s}^{-1}$ at $0.5 \mathrm{~km}$ or $<-0.1 \mathrm{~m} \mathrm{~s}^{-1}$ at $50 \mathrm{~m}$ and reflectivity $>20 \mathrm{dBZ}$ between the surface and $0.5 \mathrm{~km}$ AGL. These updraft and downdraft trajectories are a small subset of the total of 1.02 million trajectories calculated at each analysis time within the relocatable $x-y$ Lagrangian analysis domains (Fig. 1b) through the surface-15 km domain depth. A grand total of $\sim 38$ million gridpoint trajectories span the 3-h period of trajectory analysis. 
The delayed appearance of heavier TS precipitation until after 0600 UTC (e.g., Figs. 10 and 11 versus Figs. 7-9) implies that snow melting did not play a crucial role in the initiation of the observed surfacebased mesoscale cold pool in the 26 June MCS.

A descending RTF flow pattern emerges during the MCS evolution. A region of rear inflow from the west intensifies and becomes increasingly more northwesterly as it approaches the back of the CL from 0400 (Fig. 7) to 0500 (Fig. 8), 0520 (Fig. 9), 0600 (Fig. 10), and 0625 UTC (Fig. 11). The observed RTF branch in the 26 June MCS thus agrees well with past studies that have documented the intensification and rearward expansion of the RTF branch during MCS maturation (Grim et al. 2009; Klimowski 1994). The 26 June RTF evolution is also consistent with the finding of Klimowski (1994) that RTF flow initially developed behind convective cores and subsequently expanded rearward relative to the forward motion of the maturing CL.

Further evidence that the 26 June MCS was surface based are the wind damage reports, with the initial report at 0521 UTC being associated with a persistent, surface-based radar-observed surging outflow feature (e.g., Fig. 9) which the above discussion in turn has related to mesoscale cold outflow. Cold pools have been shown to be a key factor in whether an MCS can produce severe surface winds, since the favorable horizontal pressure gradients in mesoscale cold pools can generate severe winds even without assistance from downdrafts (Bryan and Weisman 2006; Kuchera and Parker 2006). Schmidt and Cotton (1989) showed that systems with stable PBLs (e.g., the NBL) can produce damaging surface winds. Hitchcock et al. (2019) found that most postconvective soundings from PECAN MCS cases contained some evidence of a cold pool at the surface, suggesting that damaging surface wind potential with nocturnal MCSs may be higher than previously thought. In a recent simulation study of the 26 June 2015 MCS, Parker et al. (2020) document the potential contribution of intense low-level mesocyclogenesis near the left-forward flank of the bowing MCS rear-inflow jet to the swath of local severe wind reports from the greater Kansas City metroplex eastward into northeastern Missouri (e.g., as documented here in Table 4).

The quasi-linear MCS and its embedded bowing segments continued to intensify throughout the IOP and developed a merged TS rain region, although the TS first formed behind the initial bowing MCS segment. Warm, moist air and ice particles were being transported rearward in the system-relative FTR flow, owing to ice particle production (e.g., DiGangi et al. 2016) and detrainment from the outer portions of strong convective updrafts and shallower updraft cores in the initial surface-based bowing MCS segment (e.g., Fig. 9). Multiple studies have shown that a strong FTR branch is necessary to develop a stratiform rain region (Smull and Houze 1987; Rutledge and Houze 1987; Watson et al. 1988). Another mechanism that potentially inhibited the quasi-linear MCS from initially developing a stratiform rain region was the initial CL-parallel southwesterly flow above the mesoscale cold pool. Since this air had previously been lifted and cooled above and downstream from the leading edge of the mesoscale cold pool (Keene and Schumacher 2013), it was drier than outflow from deep moist CL updrafts.

Parker (2008) simulated the progression of a surfacebased squall line through distinct phases as it moved through an environment that was cooling relative to the intensity of its internal mesoscale cold pool. The simulated MCS progressed through a temporal sequence of strengthening, quasi-steady, stalling, and elevated phases. These simulated MCS phases were modulated by the presence of a surface-based cold pool and densitycurrent lifting prior to the stalling phase, and followed by elevated, bore-like lifting after the stalling phase (Parker 2008). Parker (2008) also showed that up to $10 \mathrm{~K}$ of cooling in the NBL was needed to cancel the thermal solenoid in the surface-based MCS cold pool and initiate the stalling phase, while Schumacher (2015) demonstrated that simulated MCSs could be surface based if provided sufficiently large BL moisture that promoted vigorous CL updrafts. In contrast, the 26 June MCS was observed to maintain an approximately $-5 \mathrm{~K}$ cold pool intensity (about half the stalling threshold obtained by Parker 2008), and thus did not transition from surfacebased to elevated during the period of observation. Instead, the 26 June MCS initiated as an elevated system similarly to the MCS studied by Marsham et al. (2011), then intensified and developed a surface-based mesoscale cold pool and subsequently intensified toward a steady state.

\section{d. Novel aspects of this case study}

This case study is the first radar analysis to incorporate as many as six mobile and one WSR-88D radar into a multi-Doppler analysis to document the evolution of a nocturnal MCS over a three and a half hour period. The main novel finding of this case study is documenting a nocturnal MCS's transition from elevated to surface based (i.e., ingesting both surface-based and elevated air parcels) long after sunset using detail radar analyses and supported by mobile mesonet, fixed mesonet, and sounding measurements. The radar analysis combined with MM data is also able to document how surface features such the KOB and TOB are not always in phase 
due to high temporal resolution of the datasets. Coordinated sounding launches allowed for observations of the ascent magnitude associated with a stationary front and for a quantitative discussion of the importance of heterogeneities in the mesoscale environment. The sounding analysis also allowed for quantifying the morphology and evolution of the ERL that preceded the MCS, which is hypothesized to be an important factor in priming the inflow environment to support MCS intensification. A central objective of PECAN is to study what drives both elevated convection and its interactions with the stable layer, as well as subsequent transition from elevated to surface-based convection without any change in the environment such as a frontal boundary crossing or a strengthening nocturnal LLJ (Geerts et al. 2017). Most studies with environmental soundings containing a stable boundary layer (in the present case augmented by a postfrontal inversion) and elevated instability tend to assume that deep, moist convection in such an environment is elevated (e.g., Rochette and Moore 1996; Trapp et al. 2001; Bryan and Weisman 2006; Horgan et al. 2007; Marsham et al. 2011). Observations from the radar analysis and MM1 measurements revealed a rare view of the initial development of the surface-based cold pool via intrusions of the developing RTF flow to the surface. To the authors' knowledge, no other MCS case study has been able to quantify the formative stages of the surfacebased mesoscale cold pool from initially discrete stormscale cold pools. This study also uniquely documented the occurrence of locally severe surface winds and an associated wind damage LSR in a traveling microburst within the surging outflow of a bowing MCS that was associated with an anticyclonic circulation.

\section{Conclusions}

Although one previous study (Marsham et al. 2011) analyzed the evolution from an elevated to a surfacebased MCS, the present study is the first to the authors' knowledge to analyze a nocturnal MCS from isolated convective cells through upscale growth and maturation with transition from elevated to surface-based structure for over three hours. A comprehensive array of available fixed and mobile assets on 25-26 June during PECAN included up to six mobile radars and two WSR-88D, as well as Kansas mesonet sites, mobile mesonets, and mobile sounding units. The multi-Doppler radar coverage has allowed for an unprecedented $3.5 \mathrm{~h}$ of $3 \mathrm{D}$ wind field synthesis, allowing a detailed analysis of MCS kinematics both as an elevated and a surface-based system.

The main conclusions derived from analyses related to the kinematics and in situ measurements in this case study of the 26 June nocturnal MCS are the following:
- Both frontal and mesoscale ascent in the environment act to moisten the ERL via isentropic upglide, priming the environment for the initial CI and later for MCS maturation and sustenance.

- Trajectory analysis between 0300 and 0330 UTC reveals that the updrafts associated with $\mathrm{CI}$ around 0300 UTC and CL development before 0330 UTC are elevated, with computed updraft inflow trajectory origins initially concentrated from 2 to $3 \mathrm{~km}$ AGL. Horizontal inflow trajectory origins are consistent with initial elevated updrafts ingesting air from the ERL, as assumed by the lifted-sounding CI analysis.

- Rear inflow develops behind the strongest convective cores prior to the development of a stratiform rain region, supporting the hypothesis that RTF flow is convectively driven.

- The mesoscale cold pool became surface based as the RTF flow descended to the surface behind the strongest convection, leading to pockets of cold rear inflow air that had reached to the surface (e.g., as measured by MM1). As the MCS strengthened, these areas merged to create a rather homogenous, expanding surface-based meso- $\beta$-scale cold pool that persisted in time and space.

- Surging outflow related to the initial bowing MCS segment becomes evident around 0440 UTC, and is associated with an anticyclonic circulation to the west of the CL and a weaker cyclonic circulation to the east. This surging outflow led to the wind damage report at 0521 UTC and enhanced convergence at the surface, thus strengthening the $\mathrm{CL}$ in that area. The wind damage report is associated with severe surface winds.

- Trajectory analysis further reveals that the largest source of inflow air into the CL updrafts after 0440 UTC is from the lowest $0.5-1 \mathrm{~km}$, supporting the kinematic and in situ analysis which revealed that the MCS transitioned from elevated to surface-based as the surface-based cold pool developed. Trajectory analysis also documented that air parcels in the NBL were able to be lifted to their local LFC.

Some provisional conclusions that are informed by the above findings, yet cannot be fully investigated due to limitations of the available observations and presented analyses, are the following:

- In the absence of a frontally lifted moisture-bearing ERL, initial CI would not have occurred due to strong convective inhibition induced by the frontal stable layer.

- The location and orientation of the initial convection hypothetically correspond to the longest sustained period of Lagrangian parcel lift within the ERL, which contained predominantly southwesterly winds. 
- The cold rear inflow that likely formed from rain evaporation and graupel melting would have been expected to be most intense within the strongest precipitation cores outside of intense, compressionally warmed convective downdrafts, partially explaining why the surface-based cold pool was initially sampled within the isolated precipitation cores following CI.

Even though the kinematic analysis did not begin until after CI, the sounding analyses support the hypothesis that weak mesoscale lifting associated with a stationary front to the south led to the formation of an ERL, which primed the environment for elevated CI. Further mesoscale ascent prior to MCS passage primed the environment to sustain the organized convection. The environment on the cold side of the stationary front would not have been conducive to elevated convection without the isentropic ascent over the stationary front. The orientation of the initial CL was parallel to the southwesterly flow in the ERL, suggesting that this orientation was favored due to air parcels experiencing the longest period of mesoscale ascent and thus the greatest likelihood of achieving their local LFCs. Thus, the air was able to rise and cool until it reached its LFC and initiated the isolated convective cells. According to the inferred flow from kinematic analyses, the inflow to the elevated convection came from $2-3 \mathrm{~km}$ AGL in the ERL, further supporting the idea that the ERL was necessary for CI.

Over the first hour of wind analyses, the initial cells combined and grew upscale into a CL. Elevated RTF flow was observed behind the strongest convective cores after CL formation as in previous studies, implying that the RTF flow was convectively driven by diabatic cooling due to storm-scale graupel melting, rain evaporation, and updraft-inflow pressure forcing rather than stratiform precipitation processes. As the system continued to strengthen and mature, the elevated RTF flow descended toward the surface and led to the first groundbased measurement of a storm scale cold pool by MM1 between 0400 and 0430 UTC. Between 0430 and 0500 UTC, these storm-scale cold pools merged to form a meso- $\beta$-scale surface-based cold pool driven by diabatic cooling. This surface-based cold pool provided sufficient lift to allow NBL parcels to be ingested by CL updrafts, leading to a CL fed mainly by parcels originating from the lowest $1 \mathrm{~km}$. Thus, provided that the diabatically driven cold pool becomes cooler than the surface-based NBL environment, it may be inferred that elevated CI above a stable boundary layer can transition toward a surface-based CL.

The dynamics that support formation of a surfacebased cold pool are probably critical for understanding the difference in propagation between elevated and surface-based storms. It is hypothesized that knowledge of the existence of surface-based mesoscale cold pools along with strong CLs and expansive TS regions would assist forecasters in anticipating the risks of flooding and severe surface winds in nocturnal MCSs. In the 26 June MCS case, the initial wind damage report at 0521 UTC was caused by surging outflow associated with a locally intense downdraft-fed traveling downburst within the first of two surface-based bowing MCS segments. Wind and/or damage reports organized in two separate subclusters corresponding to the respective bowing segments, with the later bowing segment producing the most severe wind reports as the MCS progressed through Topeka and the greater Kansas City metropolitan area (Parker et al. 2020).

A follow-on study of the 26 June MCS will detail results from a diabatic Lagrangian analysis (DLA) using the kinematic analyses presented here to obtain a thermal-microphysical retrieval by integrating continuity equations for heat and water substance along the Lagrangian air trajectories (e.g., Miller 2018). The DLA results will facilitate analysis and interpretation of the thermodynamics and microphysics of the 26 June MCS, yielding new insights into the potential formation processes and roles of the mesoscale cold pool in developing the MCS and assisting its transition from an elevated to a surface-based system. Additional future research on this case will involve some combination of radar-analysis data assimilation and pure simulation of the 26 June MCS to better understand the dynamical MCS forcing processes, including special foci on mesoscale cold pool development, the role of the postfrontal ERL priming to stimulate the elevated to surface-based MCS transition and intensification, and the development of severe surface winds.

Acknowledgments. The authors gratefully acknowledge each of the participants and PIs involved in data collection and support during PECAN and the several parent institutions that lent their facilities to the project. In particular, we thank Dr. Russ Schumacher, Dr. Matt Parker, and Dr. Michael Coniglio for their expert coordination of the mobile sounding vehicles and mobile mesonets. We also thank Dr. Kevin Haghi and Dr. Michael Biggerstaff for their successfully coordinating a challenging mobile radar deployment in this case. The authors thank A. Addison Alford for his guidance in utilizing Solo and Py-ART. The authors also acknowledge NSF and the NSSL Director's Discretionary Research Fund (DDRF) for their overarching funding support of this project. This research was funded by NSF Grant AGS-1359726. Additional funding was provided 
by NOAA/Office of Oceanic and Atmospheric Research under NOAA-University of Oklahoma Cooperative Agreement NA11OAR4320072, U.S. Department of Commerce.

\section{REFERENCES}

Altube, P., J. Bech, O. Argemi, T. Rigo, N. Pineda, S. Collis, and J. Helmus, 2016: Correction of dual-PRF Doppler velocity outliers in the presence of aliasing. J. Atmos. Oceanic Technol., 34, 1529-1543, https://doi.org/10.1175/JTECH-D-16-0065.1.

Bernstein, B. C., and R. H. Johnson, 1994: A dual-Doppler radar study of an OK PRE-STORM heat burst event. Mon. Wea. Rev., 122, 259-273, https://doi.org/10.1175/1520-0493(1994) $122<0259$ :ADDRSO $>2.0 . \mathrm{CO} ; 2$.

Betts, A. K., 1984: Boundary layer thermodynamics of a High Plains severe storm. Mon. Wea. Rev., 112, 2199-2211, https:// doi.org/10.1175/1520-0493(1984)112<2199:BLTOAH>2.0.CO;2.

Biggerstaff, M. I., 2016a: SMART R-1 radar data, DORADE format (version 1.0). UCAR/NCAR-Earth Observing Laboratory, accessed 1 June 2016, https://doi.org/10.5065/D6C53J0T.

_ 2016b: SMART R-2 Radar Data, DORADE format (version 1.0). UCAR/NCAR-Earth Observing Laboratory, accessed 1 June 2016, https://doi.org/10.5065/D67D2S83.

_- and R. A. Houze, 1991: Kinematic and precipitation structure of the 10-11 June 1985 squall line. Mon. Wea. Rev., 119, 3066-3079, https://doi.org/10.1175/1520-0493(1991)119<3066: MVSOTJ $>2.0 . \mathrm{CO} ; 2$.

— and _ - 1993: Kinematics and microphysics of the transition zone of the 10-11 June 1985 squall line. J. Atmos. Sci., 50, 3091-3110, https://doi.org/10.1175/1520-0469(1993)050<3091: KAMOTT $>2.0 . \mathrm{CO} ; 2$.

- , and Coauthors, 2005: The Shared Mobile Atmospheric Research and Teaching Radar: A collaboration to enhance research and teaching. Bull. Amer. Meteor. Soc., 86, 1263-1274, https://doi.org/10.1175/BAMS-86-9-1263.

Billings, J. M., and M. D. Parker, 2012: Evolution and maintenance of the 22-23 June 2003 nocturnal convection during BAMEX. Wea. Forecasting, 27, 279-300, https://doi.org/10.1175/WAFD-11-00056.1.

Bonner, W. D., 1968: Climatology of the low level jet. Mon. Wea. Rev., 96, 833-850, https://doi.org/10.1175/1520-0493(1968) 096<0833:COTLLJ > 2.0.CO;2.

Braun, S. A., and R. A. Houze, 1994: The transition zone and secondary maximum of radar reflectivity behind a midlatitude squall line: Results retrieved from Doppler radar data. J. Atmos. Sci., 51, 2733-2755, https://doi.org/10.1175/ 1520-0469(1994)051<2733:TTZASM>2.0.CO;2.

Bryan, G. H., and M. D. Parker, 2010: Observations of a squall line and its near environment using high-frequency rawinsonde launches during VORTEX2. Mon. Wea. Rev., 138, 4076-4097, https://doi.org/10.1175/2010MWR3359.1.

— , and M. L. Weisman, 2006: Mechanisms for the production of severe surface winds in a simulation of an elevated convective system. 23rd Conf. on Severe Local Storms, St. Louis, MO, Amer. Meteor. Soc., 7.5, https://ams.confex.com/ams/23SLS/ techprogram/paper_115224.htm.

Carbone, R. E., and J. D. Tuttle, 2008: Rainfall occurrence in the U.S. warm season: The diurnal cycle. J. Climate, 21, 4132 4146, https://doi.org/10.1175/2008JCLI2275.1.

_- J. W. Conway, N. A. Crook, and M. W. Moncrieff, 1990: The generation and propagation of a nocturnal squall line.
Part I: Observations and implications for mesoscale predictability. Mon. Wea. Rev., 118, 26-49, https://doi.org/10.1175/ 1520-0493(1990)118<0026:TGAPOA $>2.0$. CO;2.

Clark, A. J., W. A. Gallus, and T. C. Chen, 2007: Comparison of diurnal precipitation cycle in convection-resolving and non-convection-resolving mesoscale models. Mon. Wea. Rev., 135, 3456-3473, https://doi.org/10.1175/MWR3467.1.

Coniglio, M. C., J. Y. Hwang, and D. J. Stensrud, 2010: Environmental factors in the upscale growth and longevity of MCSs derived from Rapid Update Cycle analyses. Mon. Wea. Rev., 138, 3514-3539, https://doi.org/10.1175/2010MWR3233.1.

Corfidi, S. F., 2003: Cold pools and MCS propagation: Forecasting the motion of downwind-developing MCSs. Wea. Forecasting, 18, 997-1017, https://doi.org/10.1175/1520-0434(2003)018<0997: CPAMPF $>2.0 . \mathrm{CO} ; 2$.

- S. J. Corfidi, and D. M. Schultz, 2008: Elevated convection and castellanus: Ambiguities, significance, and questions. Wea. Forecasting, 23, 1280-1303, https://doi.org/10.1175/ 2008WAF2222118.1.

Davis, C. A., K. W. Manning, R. E. Carbone, S. B. Trier, and J. D. Tuttle, 2003: Coherence of warm-season continental rainfall in numerical weather prediction models. Mon. Wea. Rev., 131, 2667-2679, https://doi.org/10.1175/1520-0493(2003)131<2667: COWCRI $>2.0 . \mathrm{CO} ; 2$

DiGangi, E., D. MacGorman, C. Ziegler, D. Betten, M. Biggerstaff, M. Bowlan, and C. Potvin, 2016: An overview of the 29 May 2012 Kingfisher supercell during DC3. J. Geophys. Res., 121, 14316-14343, https://doi.org/10.1002/2016JD025690.

Doswell, C. A., III, and M. J. Haugland, 2007: A comparison of two cold fronts-Effects of the planetary boundary layer on the mesoscale. Electronic J. Severe Storms Meteor., 2 (4), http:// www.ejssm.org/ojs/index.php/ejssm/article/viewarticle/30/24.

Engerer, N. A., D. J. Stensrud, and M. C. Coniglio, 2008: Surface characteristics of observed cold pools. Mon. Wea. Rev., 136, 4839-4849, https://doi.org/10.1175/2008MWR2528.1.

Fujita, T. T., 1981: Tornadoes and downbursts in the context of generalized planetary scales. J. Atmos. Sci., 38, 1511-1534, https:// doi.org/10.1175/1520-0469(1981)038<1511:TADITC >2.0.CO;2.

, and R. M. Wakimoto, 1981: Five scales of airflow associated with a series of downbursts on 16 July 1980. Mon. Wea. Rev., 109, 1438-1456, https://doi.org/10.1175/1520-0493(1981)109<1438: FSOAAW $>2.0 . \mathrm{CO} ; 2$

Gale, J. J., J. W. A. Gallus, and K. A. Jungbluth, 2002: Toward improved prediction of mesoscale convective system dissipation. Wea. Forecasting, 17, 856-872, https://doi.org/10.1175/ 1520-0434(2002)017<0856:TIPOMC > 2.0.CO;2.

Geerts, B., 2013: Plains Elevated Convection at Night (PECAN) experimental design overview. NOAA, $37 \mathrm{pp}$., http://wwwdas.uwyo.edu/ geerts/pecan/proposal/PECAN_EDO.pdf.

, and Coauthors, 2017: The 2015 Plains Elevated Convection At Night Field Project. Bull. Amer. Meteor. Soc., 98, 767-786, https://doi.org/10.1175/BAMS-D-15-00257.1.

Grady, R. L., and J. Verlinde, 1997: Triple-Doppler analysis of a discretely propagating, long-lived, High Plains squall line. J. Atmos. Sci., 54, 2729-2748, https://doi.org/10.1175/15200469(1997)054<2729:TDAOAD>2.0.CO;2.

Grim, J. A., R. M. Rauber, G. M. McFarquhar, B. F. Jewett, and D. P. Jorgensen, 2009: Development and forcing of the rear inflow jet in a rapidly developing and decaying squall line during BAMEX. Mon. Wea. Rev., 137, 1206-1229, https:// doi.org/10.1175/2008MWR2503.1.

Helmus, J. J., and S. M. Collis, 2016: The Python ARM Radar Toolkit (Py-ART), a library for working with weather radar 
data in the Python programming language. J. Open Res. Software, 4, e25, https://doi.org/10.5334/jors.119.

Hitchcock, S. M., R. S. Schumacher, G. R. Herman, M. C. Coniglio, M. D. Parker, and C. L. Ziegler, 2019: Evolution of pre- and postconvective environmental profiles from mesoscale convective systems during PECAN. Mon. Wea. Rev., 147, 2329 2354, https://doi.org/10.1175/MWR-D-18-0231.1.

Horgan, K. L., D. M. Schultz, J. E. Hales, S. F. Corfidi, and R. H. Jones, 2007: A five-year climatology of elevated severe convective storms in the United States east of the Rocky Mountains. Wea. Forecasting, 22, 1031-1044, https://doi.org/10.1175/ WAF1032.1.

Houze, R. A., S. A. Rutledge, M. I. Biggerstaff, and B. F. Smull, 1989: Interpretation of Doppler weather radar displays of midlatitude mesoscale convective systems. Bull. Amer. Meteor. Soc., 70, 608-619, https://doi.org/10.1175/15200477(1989)070<0608:IODWRD>2.0.CO;2.

— B. F. Smull, and P. Dodge, 1990: Mesoscale organization of springtime rainstorms in Oklahoma. Mon. Wea. Rev., 118, 613-654, https://doi.org/10.1175/1520-0493(1990)118<0613: MOOSRI $>2.0 . \mathrm{CO} ; 2$.

Jirak, I. L., and W. R. Cotton, 2007: Observational analysis of the predictability of mesoscale convective systems. Wea. Forecasting, 22, 813-838, https://doi.org/10.1175/WAF1012.1.

Johns, R. H., and W. D. Hirt, 1987: Derechos: Widespread convectively induced windstorms. Wea. Forecasting, 2, 32-49, https://doi.org/10.1175/1520-0434(1987)002<0032:DWCIW> 2.0.CO;2.

Jorgensen, D. P., and B. F. Smull, 1993: Mesovortex circulations seen by airborne Doppler radar within a bow-echo mesoscale convective system. Bull. Amer. Meteor. Soc., 74, 2146-2157, https:// doi.org/10.1175/1520-0477(1993)074<2146:MCSBAD>2.0.CO;2.

_ M. A. LeMone, and S. B. Trier, 1997: Structure and evolution of the 22 February 1993 TOGA COARE squall line: Aircraft observations of precipitation, circulation, and surface energy fluxes. J. Atmos. Sci., 54, 1961-1985, https://doi.org/10.1175/ 1520-0469(1997)054<1961:SAEOTF>2.0.CO;2.

Keene, K. M., and R. S. Schumacher, 2013: The bow and arrow mesoscale convective structure. Mon. Wea. Rev., 141, 16481672, https://doi.org/10.1175/MWR-D-12-00172.1.

Kessinger, C. J., P. S. Ray, and C. E. Hane, 1987: The Oklahoma squall line of 19 May 1977. Part I: A multiple Doppler analysis of convective and stratiform structure. J. Appl. Meteor., 44, 2840-2864, https://doi.org/10.1175/1520-0469(1987)044<2840: TOSLOM $>2.0 . \mathrm{CO} ; 2$.

Klein, P., and Coauthors, 2016: Mobile PISA 1 OU/NSSL CLAMPS radiosonde data (version 1.0). UCAR/NCAREarth Observing Laboratory, accessed 1 June 2016, https:// doi.org/10.5065/D6416VDH.

Klimowski, B. A., 1994: Initiation and development of rear inflow within the 28-29 June 1989 North Dakota mesoconvective system. Mon. Wea. Rev., 122, 765-779, https://doi.org/10.1175/ 1520-0493(1994)122<0765:IADORI >2.0.CO;2.

Knievel, J. C., D. A. Ahijevych, and K. W. Manning, 2004: Using temporal modes of rainfall to evaluate the performance of a numerical weather prediction model. Mon. Wea. Rev., 132, 2995-3009, https://doi.org/10.1175/MWR2828.1.

Kuchera, E. L., and M. D. Parker, 2006: Severe convective wind environments. Wea. Forecasting, 21, 595-612, https://doi.org/ 10.1175/WAF931.1.

Maddox, R. A., 1980: Mesoscale convective complexes. Bull. Amer. Meteor. Soc., 61, 1374-1387, https://doi.org/10.1175/ 1520-0477(1980)061<1374:MCC>2.0.CO;2.
__ 1983: Large-scale meteorological conditions associated with midlatitide, mesoscale convective complexes. Mon. Wea. Rev., 111, 1475-1493, https://doi.org/10.1175/1520-0493(1983) $111<1475$ :LSMCAW >2.0.CO;2.

Majcen, M., P. Markowski, Y. Richardson, D. Dowell, and J. Wurman, 2008: Multipass objective analysis of Doppler radar data. J. Atmos. Oceanic Technol., 25, 1845-1858, https:// doi.org/10.1175/2008JTECHA1089.1.

Marsham, J. H., S. B. Trier, T. M. Weckwerth, and J. W. Wilson, 2011: Observations of elevated convection initiation leading to a surface-based squall line during 13 June IHOP_2002. Mon. Wea. Rev., 139, 247-271, https://doi.org/10.1175/ 2010MWR3422.1.

McAnelly, R. L., J. E. Nachamkin, W. R. Cotton, and M. E. Nicholls, 1997: Upscale evolution of MCSs: Doppler radar analysis and analytical investigation. Mon. Wea. Rev., 125, 1083-1110, https://doi.org/10.1175/1520-0493(1997)125<1083: UEOMDR $>2.0 . \mathrm{CO} ; 2$.

Miller, R. L., 2018: Kinematics, thermodynamics, and microphysics of the 25-26 June 2015 Kansas MCS during PECAN. M.S. thesis, University of Oklahoma, 154 pp., https://shareok.org/ handle/11244/299940.

Nachamkin, J. E., R. L. McAnelly, and W. R. Cotton, 1994: An observational analysis of a developing mesoscale convective complex. Mon. Wea. Rev., 122, 1168-1188, https://doi.org/ 10.1175/1520-0493(1994)122<1168:AOAOAD>2.0.CO;2.

,-- , and $\longrightarrow$ 2000: Interactions between a developing mesoscale convective system and its environment. Part I: Observational analysis. Mon. Wea. Rev., 128, 1205-1224, https:// doi.org/10.1175/1520-0493(2000)128<1205:IBADMC>2.0.CO;2.

Nallapareddy, A., A. Shapiro, and J. J. Gourley, 2011: A climatology of nocturnal warming events associated with coldfrontal passages in Oklahoma. J. Appl. Meteor. Climatol., 50, 2042-2061, https://doi.org/10.1175/JAMC-D-11-020.1.

O'Brien, J. J., 1970: Alternative solutions to the classical vertical velocity problem. J. Appl. Meteor., 9, 197-203, https://doi.org/ 10.1175/1520-0450(1970)009<0197:ASTTCV>2.0.CO;2.

Parker, M. D., 2008: Response of simulated squall lines to low-level cooling. J. Atmos. Sci., 65, 1323-1341, https://doi.org/10.1175/ 2007JAS2507.1.

_ B. S. Borchardt, R. L. Miller, and C. L. Ziegler, 2020: Simulated evolution and severe wind production by the 2526 June 2015 nocturnal MCS from PECAN. Mon. Wea. Rev., 148, 183-209, https://doi.org/10.1175/MWR-D-19-0072.1.

Peters, J. M., E. R. Nielsen, M. D. Parker, S. M. Hitchcock, and R. S. Schumacher, 2017: The impact of low-level moisture errors on model forecasts of an MCS observed during PECAN. Mon. Wea. Rev., 145, 3599-3624, https://doi.org/10.1175/MWR-D-16-0296.1.

Rasmussen, E. N., and S. A. Rutledge, 1993: Evolution of quasitwo-dimensional squall lines. Part I: Kinematic and reflectivity structure. J. Atmos. Sci., 50, 2584-2606, https://doi.org/ 10.1175/1520-0469(1993)050<2584:EOQTDS > 2.0.CO;2.

Ray, P. S., and K. L. Sangren, 1983: Multiple-Doppler radar network design. J. Climate Appl. Meteor., 22, 1444-1454, https:// doi.org/10.1175/1520-0450(1983)022<1444:MDRND>2.0.CO;2.

— , K. K. Wagner, K. W. Johnson, J. J. Stephens, W. C. Bumgarner, and E. A. Mueller, 1978: Triple-Doppler observations of a convective storm. J. Appl. Meteor., 17, 1201-1212, https://doi.org/10.1175/1520-0450(1978)017<1201:TDOOAC > 2.0.CO;2.

_ J. J. Stephens, and K. W. Johnson, 1979: Multiple-Doppler radar network design. J. Appl. Meteor., 18, 706-710, https:// doi.org/10.1175/1520-0450(1979)018<0706:MDRND>2.0.CO;2. 
_ C. L. Ziegler, W. Bumgarner, and R. J. Serafin, 1980: Singleand multiple-Doppler radar observations of tornadic storms. Mon. Wea. Rev., 108, 1607-1625, https://doi.org/10.1175/15200493(1980)108<1607:SAMDRO > 2.0.CO;2.

Rochette, S. M., and J. T. Moore, 1996: Initiation of an elevated mesoscale convective system associated with heavy rainfall. Wea. Forecasting, 11, 443-457, https://doi.org/10.1175/15200434(1996)011<0443:IOAEMC>2.0.CO;2.

Rotunno, R., J. B. Klemp, and M. L. Weisman, 1988: A theory for strong, long-lived squall lines. J. Atmos. Sci., 45, 463-485, https://doi.org/10.1175/1520-0469(1988)045<0463: ATFSLL $>2.0 . \mathrm{CO} ; 2$.

Roux, F., 1988: The West African squall line observed on 23 June 1981 during COPT 81: Kinematics and thermodynamics of the convective region. J. Atmos. Sci., 45, 406-426, https://doi.org/ 10.1175/1520-0469(1988)045<0406:TWASLO > 2.0.CO;2.

Rutledge, S. A., and R. A. Houze, 1987: A diagnostic modelling study of the trailing stratiform region of a midlatitude squall line. J. Atmos. Sci., 44, 2640-2656, https://doi.org/10.1175/ 1520-0469(1987)044<2640:ADMSOT>2.0.CO;2.

— — - M. I. Biggerstaff, and T. Matejka, 1988: The Oklahoma-Kansas mesoscale convective system of 10 11 June 1985: Precipitation structure and single-Doppler radar analysis. Mon. Wea. Rev., 116, 1409-1430, https://doi.org/ 10.1175/1520-0493(1988)116<1409:TOMCSO > 2.0.CO;2.

Schmidt, J. M., and W. R. Cotton, 1989: A High Plains squall line associated with severe surface winds. J. Atmos. Sci., 46, 281-302, https://doi.org/10.1175/1520-0469(1989)046<0281: AHPSLA $>2.0 . \mathrm{CO} ; 2$.

Schumacher, R. S., 2015: Sensitivity of precipitation accumulation in elevated convective systems to small changes in low-level moisture. J. Atmos. Sci., 72, 2507-2524, https://doi.org/10.1175/ JAS-D-14-0389.1.

Schuur, T. J., and S. A. Rutledge, 2000: Electrification of stratiform regions in mesoscale convective systems. Part I: An observational comparison of symmetric and asymmetric MCSs. J. Atmos. Sci., 57, 1961-1982, https://doi.org/10.1175/15200469(2000)057<1961:EOSRIM > 2.0.CO;2.

Scott, J. D., and S. A. Rutledge, 1995: Doppler radar observations of an asymmetric mesoscale convective system and associated vortex couplet. Mon. Wea. Rev., 123, 34373457, https://doi.org/10.1175/1520-0493(1995)123<3437: DROOAA $>2.0 . \mathrm{CO} ; 2$.

Smull, B. F., and R. A. Houze, 1985: A midlatitude squall line with a trailing region of stratiform rain: Radar and satellite observations. Mon. Wea. Rev., 113, 117-133, https://doi.org/ 10.1175/1520-0493(1985)113<0117:AMSLWA > 2.0.CO;2.

_, and _ 1987: Dual-Doppler radar analysis of a midlatitude squall line with a trailing region of stratiform rain. J. Atmos. Sci., 44, 2128-2149, https://doi.org/10.1175/1520-0469(1987) 044<2128:DDRAOA > 2.0.CO;2.

— , and J. A. Augustine, 1993: Multiscale analysis of a mature mesoscale convective complex. Mon. Wea. Rev., 121, 103-132, https://doi.org/10.1175/1520-0493(1993)121<0103:MAOAMM> 2.0.CO;2.

Straka, J. M., E. N. Rasmussen, and S. E. Fredrickson, 1996: A mobile mesonet for finescale meteorological observations. J. Atmos. Oceanic Technol., 13, 921-936, https://doi.org/ 10.1175/1520-0426(1996)013<0921:AMMFFM>2.0.CO;2.

Tabary, P., L. Perier, J. Gagneux, and J. Parent-Du-Chatelet, 2005: Test of a staggered PRT scheme for the French radar network. J. Atmos. Oceanic Technol., 22, 352-364, https://doi.org/ 10.1175/JTECH1709.1.
Trapp, R. J., D. M. Schultz, A. V. Ryzhkov, and R. L. Holle, 2001: Multiscale structure and evolution of an Oklahoma winter precipitation event. Mon. Wea. Rev., 129, 486-501, https://doi.org/ 10.1175/1520-0493(2001)129<0486:MSAEOA > 2.0.CO;2.

Trier, S. B., and D. B. Parsons, 1993: Evolution of environmental conditions preceding the development of a nocturnal mesoscale convective complex. Mon. Wea. Rev., 121, 1078-1098, https:// doi.org/10.1175/1520-0493(1993)121<1078:EOECPT>2.0.CO;2.

_- J. H. Marsham, C. A. Davis, and D. A. Ahijevych, 2011: Numerical simulations of the postsunrise reorganization of a nocturnal mesoscale convective system during 13 June IHOP_2002. J. Atmos. Sci., 68, 2988-3011, https://doi.org/ 10.1175/JAS-D-11-0112.1.

UCAR/NCAR-Earth Observing Laboratory, 2015: Kansas Mesonet Data (version 1.0). UCAR/NCAR-Earth Observing Laboratory, accessed 1 June 2016, https://data.eol.ucar.edu/ dataset/485.017.

2016: MP4 NCAR/EOL QC Soundings (version 2.0). UCAR/NCAR-Earth Observing Laboratory, accessed 1 June 2016, https://doi.org/10.5065/D6707ZNV.

Wade, A. R., M. C. Coniglio, and C. L. Ziegler, 2018: Comparison of near- and far-field supercell inflow environments using radiosonde observations. Mon. Wea. Rev., 146, 2403-2415, https://doi.org/10.1175/MWR-D-17-0276.1.

Wallace, J. M., 1975: Diurnal variations in precipitation and thunderstorm frequency over the conterminous United States. Mon. Wea. Rev., 103, 406-419, https://doi.org/10.1175/15200493(1975)103<0406:DVIPAT > 2.0.CO;2.

Watson, A. I., J. Meitín, and J. B. Cunning, 1988: Evolution of the kinematic structure and precipitation characteristics of a mesoscale convective system on 20 May 1979. Mon. Wea. Rev., 116, 1555-1567, https://doi.org/10.1175/1520-0493(1988)116<1555: EOTKSA $>2.0 . \mathrm{CO} ; 2$.

Waugh, S. M., 2012: The "U-Tube": An improved aspirated temperature system for mobile meteorological observations, especially in severe weather. M.S. thesis, University of Oklahoma, Norman, OK, 76 pp., http://hdl.handle.net/11244/24679].

, and C. Ziegler, 2017: NSSL Mobile Mesonet Data (version 1.1). UCAR/NCAR-Earth Observing Laboratory, accessed 1 June 2016, https://doi.org/10.5065/D64M92RG.

Wetzel, P. J., W. R. Cotton, and R. L. McAnelly, 1983: A longlived mesoscale convective complex. Part II: Evolution and structure of the mature complex. Mon. Wea. Rev., 111, 1919-1937, https://doi.org/10.1175/1520-0493(1983)111<1919: ALLMCC $>2.0 . \mathrm{CO} ; 2$.

Wurman, J., J. Straka, E. Rasmussen, M. Randall, and A. Zahrai, 1997: Design and deployment of a portable, pencil-beam, pulsed, 3-cm Doppler radar. J. Atmos. Oceanic Technol., 14, 1502-1512, https://doi.org/10.1175/1520-0426(1997)014<1502: DADOAP $>2.0 . \mathrm{CO} ; 2$

Zheng, Y., Q. Xu, and D. J. Stensrud, 1995: A numerical simulation of the 7 May 1985 mesoscale convective system. Mon. Wea. Rev., 123, 1781-1799, https://doi.org/10.1175/1520-0493(1995) $123<1781$ :ANSOTM $>2.0 . \mathrm{CO} ; 2$.

Ziegler, C. L., 1999: Issues in forecasting mesoscale convective systems: An observational and modeling perspective. Storms, R. Pielke Jr. and R. Pielke Sr, Eds., Vol. 2, Routledge Press, 26-42.

__ 2013a: A diabatic Lagrangian technique for the analysis of convective storms. Part I: Description and validation via an observing system simulation experiment. J. Atmos. Oceanic Technol., 30, 2248-2265, https://doi.org/10.1175/ JTECH-D-12-00194.1. 
2013b: A diabatic Lagrangian technique for the analysis of convective storms. Part II: Application to a radar-observed storm. J. Atmos. Oceanic Technol., 30, 2266-2280, https:// doi.org/10.1175/JTECH-D-13-00036.1.

— 2016: NOXP Radar Data in DORADE format (version 1.0). UCAR/NCAR-Earth Observing Laboratory, accessed 1 June 2016, https://data.eol.ucar.edu/dataset/485.066.

_, and E. N. Rasmussen, 1998: The initiation of moist convection at the dryline: Forecasting issues from a case study perspective. Wea. Forecasting, 13, 1106-1131, https://doi.org/ 10.1175/1520-0434(1998)013<1106:TIOMCA > 2.0.CO;2.

__ P. S. Ray, and N. C. Knight, 1983: Hail growth in an Oklahoma multicell storm. J. Atmos. Sci., 40, 1768-1791, https://doi.org/ 10.1175/1520-0469(1983)040<1768:HGIAOM > 2.0.CO;2.

_- D. MacGorman, J. Dye, and P. Ray, 1991: A model evaluation of non-inductive graupel-ice charging in the early electrification of a mountain thunderstorm. J. Geophys. Res., 96, 12 833-12 855, https://doi.org/10.1029/91JD01246.

, T. Lee, and R. A. Pielke Sr., 1997: Convective initiation at the dryline: A modeling study. Mon. Wea. Rev., 125, 1001-1026, https:// doi.org/10.1175/1520-0493(1997)125<1001:CIATDA>2.0.CO;2.

D. Kennedy, and E. N. Rasmussen, 2004: A wireless network for collection and synthesis of mobile mesoscale weather observations. J. Atmos. Oceanic Technol., 21, 1659-1670, https:// doi.org/10.1175/JTECH1678.1.

_- E. Mansell, J. Straka, D. MacGorman, and D. Burgess, 2010: The impact of spatial variations of low-level stability on the life cycle of a simulated supercell storm. Mon. Wea. Rev., 138, 1738-1766, https://doi.org/10.1175/2009MWR3010.1.

_ , and Coauthors, 2016: CSU/NCSU/NSSL MGAUS Radiosonde Data (version 3.0). UCAR/NCAR-Earth Observing Laboratory, accessed 1 June 2016, https://doi.org/10.5065/D6W66HXN. 